Portland State University

PDXScholar

$12-1-2008$

\title{
Understanding and Measuring Bicycling Behavior: a Focus on Travel Time and Route Choice
}

Jennifer Dill

Portland State University, jdill@pdx.edu

John Gliebe

Portland State University

Follow this and additional works at: https://pdxscholar.library.pdx.edu/usp_fac

Part of the Transportation Commons, and the Urban Studies and Planning Commons Let us know how access to this document benefits you.

\section{Citation Details}

Jennifer Dill and John Gliebe, "Understanding and measuring bicycling behavior: a focus on travel time and route choice," Final report OTREC-RR-08-03 prepared for Oregon Transportation Research and Education Consortium (OTREC), December 2008. http://dx.doi.org/10.15760/trec.151

This Report is brought to you for free and open access. It has been accepted for inclusion in Urban Studies and Planning Faculty Publications and Presentations by an authorized administrator of PDXScholar. Please contact us if we can make this document more accessible: pdxscholar@pdx.edu. 


\section{5
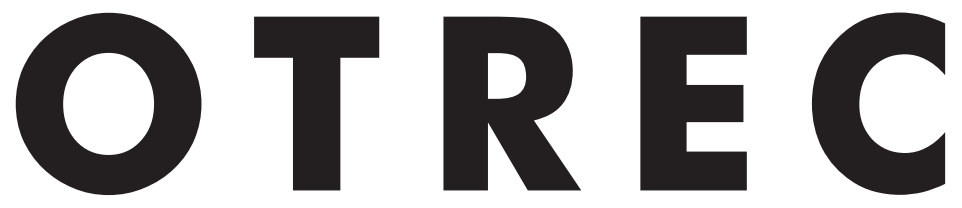 \\ FINAL REPORT}

Understanding and Measuring Bicycling Behavior: a Focus on Travel Time and Route Choice

OTREC-RR-08-03 December 2008 


\title{
UNDERSTANDING AND MEASURING BICYCLING BEHAVIOR: \\ A FOCUS ON TRAVEL TIME AND ROUTE CHOICE
}

Final Report

OTREC-RR-08-03

\author{
by \\ Jennifer Dill, Ph.D. \\ John Gliebe, Ph.D. \\ Portland State University \\ for \\ Oregon Transportation Research \\ and Education Consortium (OTREC) \\ P.O. Box 751 \\ Portland, OR 97207

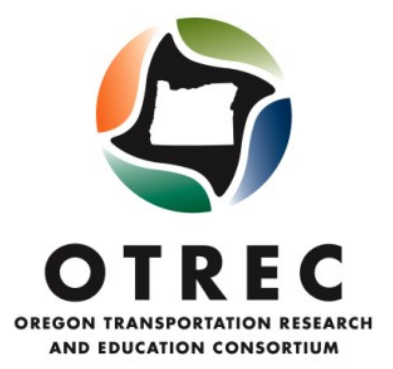

December 2008 



\begin{tabular}{|c|c|c|c|c|}
\hline \multicolumn{5}{|c|}{ Technical Report Documentation Page } \\
\hline $\begin{array}{l}\text { 1. Report No. } \\
\text { OTREC-RR-08-03 }\end{array}$ & \multicolumn{2}{|c|}{ 2. Government Accession No. } & \multicolumn{2}{|c|}{ 3. Recipient's Catalog No. } \\
\hline \multirow{2}{*}{\multicolumn{3}{|c|}{$\begin{array}{l}\text { 4. Title and Subtitle } \\
\text { Understanding and Measuring Bicycling Behavior: A Focus on Travel Time and Route choice } \\
\text { Final Report }\end{array}$}} & \multirow{2}{*}{\multicolumn{2}{|c|}{$\begin{array}{l}\text { 5. Report Date } \\
\text { December } 2008\end{array}$}} \\
\hline & & & & \\
\hline \multicolumn{3}{|l|}{$\begin{array}{l}\text { 7. Author(s) } \\
\text { Jennifer Dill, Ph.D. } \\
\text { John Gliebe, Ph.D. }\end{array}$} & \multicolumn{2}{|c|}{ 8. Performing Organization Report No. } \\
\hline \multirow{2}{*}{\multicolumn{3}{|c|}{$\begin{array}{l}\text { 9. Performing Organization Name and Address } \\
\text { Center for Urban Studies/Center for Transportation Studies } \\
\text { Portland State University } \\
\text { PO Box } 751 \\
\text { Portland, OR 97201-0751 }\end{array}$}} & \multicolumn{2}{|c|}{ 10. Work Unit No. (TRAIS) } \\
\hline & & & \multicolumn{2}{|c|}{ 11. Contract or Grant No. } \\
\hline \multicolumn{3}{|c|}{ 12. Sponsoring Agency Name and Address } & \multicolumn{2}{|c|}{ 13. Type of Report and Period Covered } \\
\hline \multicolumn{2}{|l|}{$\begin{array}{l}\text { Oregon Transportation Research } \\
\text { and Education Consortium (OTREC) } \\
\text { P.O. Box } 751 \\
\text { Portland, Oregon } 97207\end{array}$} & & \multicolumn{2}{|c|}{ 14. Sponsoring Agency Code } \\
\hline \multicolumn{5}{|l|}{ 15. Supplementary Notes } \\
\hline \multicolumn{5}{|c|}{$\begin{array}{l}\text { 16. Abstract } \\
\text { With rates of obesity, heart disease, and related health problems increasing in the U.S., many policy makers are looking for ways to increase } \\
\text { physical activity in everyday life. Using a bicycle instead of a motor vehicle for a portion of everyday travel could help address these problems. } \\
\text { This research aims to fill a gap in the existing literature on the effect of different types of infrastructure, such as bicycle lanes or paths, on } \\
\text { bicycling. The project used global positioning system (GPS) techology to record where a sample of } 164 \text { adults in the Portland, OR region rode } \\
\text { their bicycles. Data was collected from March through November } 2007 \text {. The participants in this study were primarily regular bicyclists who } \\
\text { usually rode more than one day per week, year-round. This report uses that data to address the four primary sets of research questions: (1) } \\
\text { How often, why, when, and where do cyclists ride? How does this vary based upon rider characteristics? (2) How do cyclists' routes differ } \\
\text { from the shortest network distance? (3) What factors influence cyclists' route choice decisions? How do personal attributes influence these } \\
\text { decisions? (4) What is the difference in travel time between bicycling and driving? }\end{array}$} \\
\hline $\begin{array}{l}\text { 17. Key Words } \\
\text { bicycling, bicycle facilities, bicycle lane } \\
\text { bikeways, cyclists, global positioning sy }\end{array}$ & $\begin{array}{l}\text { ycle routes, bicycle travel, } \\
\text { route choice }\end{array}$ & \multicolumn{3}{|c|}{$\begin{array}{l}\text { 18. Distribution Statement } \\
\text { No restrictions. Copies available from OTREC: } \\
\text { www.otrec.us }\end{array}$} \\
\hline $\begin{array}{l}\text { 19. Security Classification (of this report) } \\
\text { Unclassified }\end{array}$ & $\begin{array}{l}\text { 20. Security Classification } \\
\text { Unclassified }\end{array}$ & page) & o. of Pages & 22. Price \\
\hline
\end{tabular}




\section{ACKNOWLEDGEMENTS}

The authors wish to thank the many research assistants whose contributions were invaluable to the project, including Matt Waddell, Daniel Costantino, Kim Voros, Dana Dickman, Hannah Kapell, Tomoko Kanai, Elizabeth Warren, Pete Collins, Mark Gilbert, and Emily Hoffer. Special thanks go to Matt Waddell, whose programming skills and dedication made the project succeed; Daniel Costantino, whose attention to detail and work with the data was invaluable; and Kim Voros, who helped develop the mapping process.

The Active Living Research program of the Robert Wood Johnson Foundation provided the funding for the first part of this project, including much of the data collection.

We also would like to thank the study participants.

\section{DISCLAIMER}

The contents of this report reflect the views of the authors, who are solely responsible for the facts and the accuracy of the material and information presented herein. This document is disseminated under the sponsorship of the U.S. Department of Transportation University Transportation Centers Program and the Active Living Research program of the Robert Wood Johnson Foundation in the interest of information exchange. The U.S. Government and the Robert Wood Johnson Foundation assume no liability for the contents or use thereof. The contents do not necessarily reflect the official views of the U.S. Government or the Robert Wood Johnson Foundation. This report does not constitute a standard, specification, or regulation. 


\section{UNDERSTANDING AND MEASURING BICYCLING BEHAVIOR: A FOCUS ON TRAVEL TIME AND ROUTE CHOICE}

\section{TABLE OF CONTENTS}

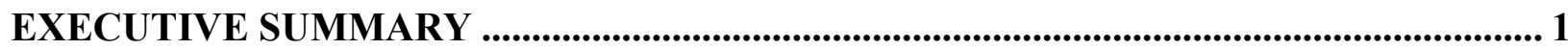

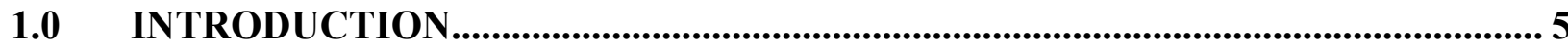

2.0 BACKGROUND AND RESEARCH OBJECTIVES ...................................................... 7

2.1 OVERVIEW OF BICYCLING BEHAVIOR ......................................................... 7

2.2 THE INFLUENCE OF INFRASTRUCTURE ON BICYCLING BEHAVIOR …............. 8

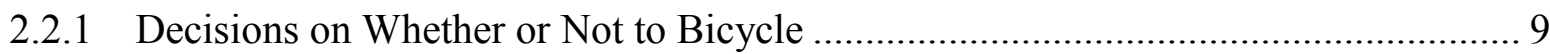

2.2.2 Route Choice Decisions .................................................................................. 9

2.3 RESEARCH OBJECTIVES ................................................................................ 11

3.0 METHODOLOGY ….................................................................................................... 13

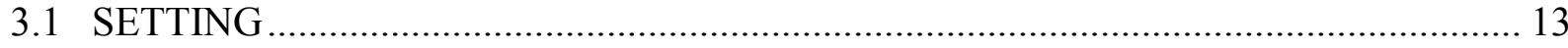

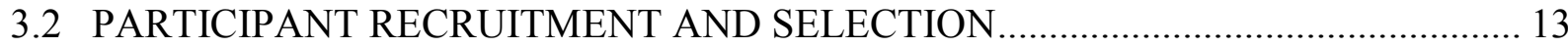

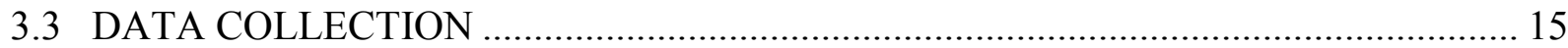

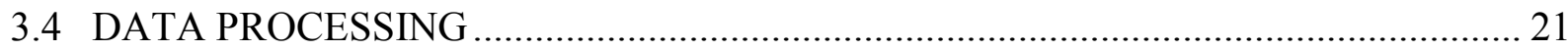

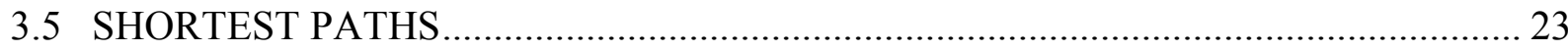

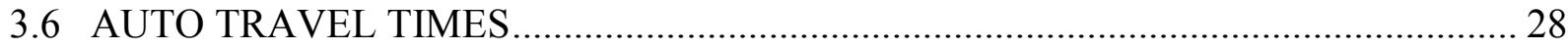

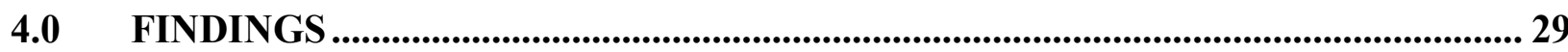

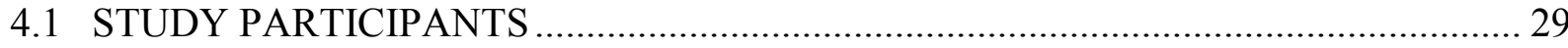

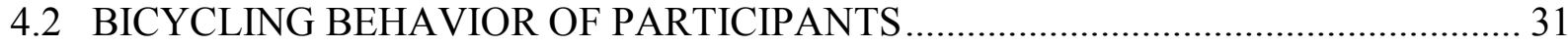

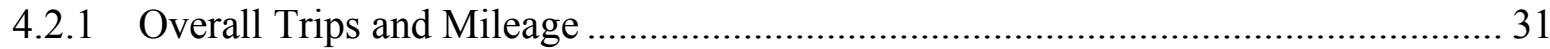

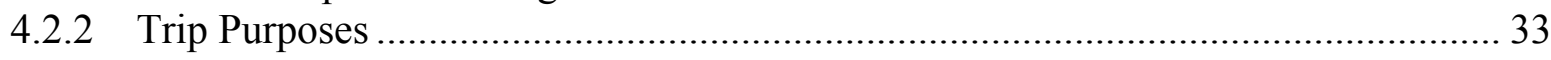

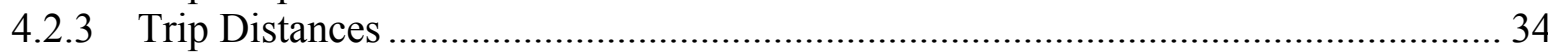

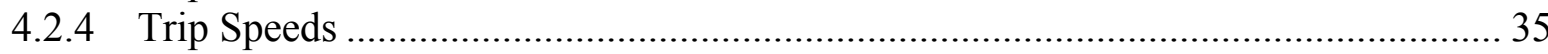

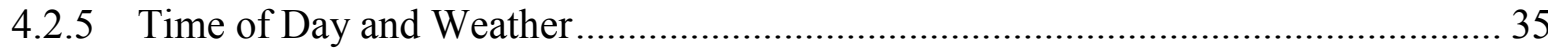

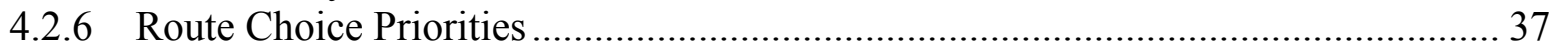

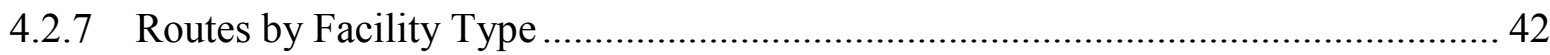

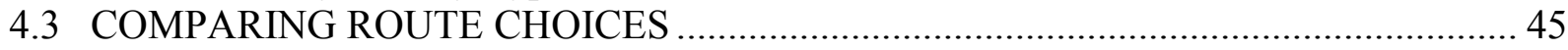

4.3.1 Observed Bicycle Route vs. Shortest Path........................................................... 45

4.3.2 Bicycle vs. Car Travel Time …………............................................................... 49

5.0 CONCLUSIONS ........................................................................................................... 51

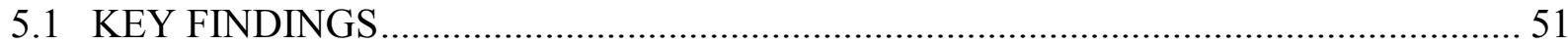

5.1.1 How Often, Why, When, and Where Do Cyclists Ride? ……………………….... 51

5.1.2 How Do Cyclists' Routes Differ from the Shortest Network Distance? .................. 51

5.1.3 How Do Cyclists Choose Their Routes? .............................................................. 52

5.1.4 How Does This Vary Based Upon Rider Characteristics? ....................................... 52

5.1.4.1 Differences between Men and Women ......................................................... 52

5.1.4.2 Difference between Infrequent and Frequent Bicyclists................................... 53

5.1.5 What Is the Difference in Travel Time between Bicycling and Driving? ................ 53 


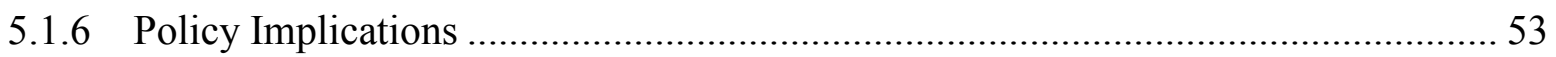

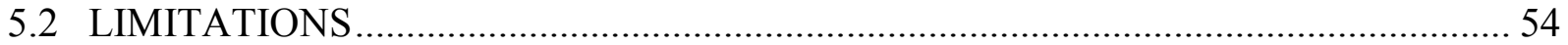

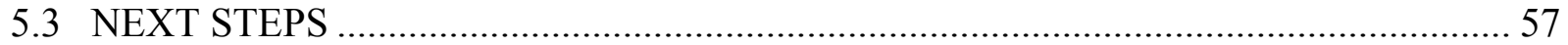

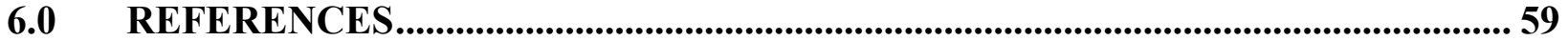




\section{LIST OF TABLES}

Table 0.1 Difference in Bicycle Travel by Facility Type, Observed vs. Shortest-Path Routes..... 2

Table 3.1 Trip Purposes and Examples Provided to Participant.................................................. 17

Table 4.1 Comparison of GPS Participants and Phone Survey Respondents, Type of Bicyclist 29

Table 4.2 Comparison of GPS Participants and Phone Survey Respondents, Frequency of

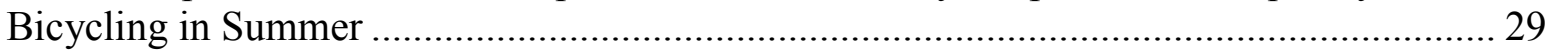

Table 4.3 Comparison of GPS Participants and Phone Survey Respondents, Frequency of

Bicycling in non-Summer Months ................................................................................... 29

Table 4.4 Comparison of GPS Participants and Phone Survey Respondents, Age ..................... 30

Table 4.5 Comparison of GPS Participants and Phone Survey Respondents, Income.................. 30

Table 4.6 Comparison of GPS Participants and Phone Survey Respondents, Sex....................... 31

Table 4.7 Number of Bicycle Trips per Day Recorded ............................................................. 31

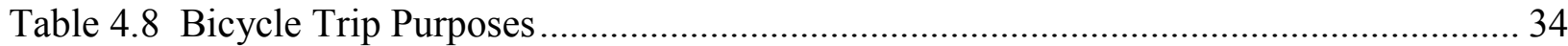

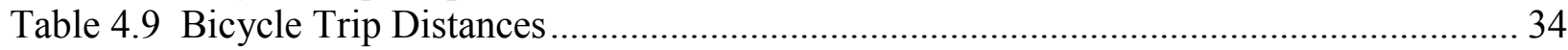

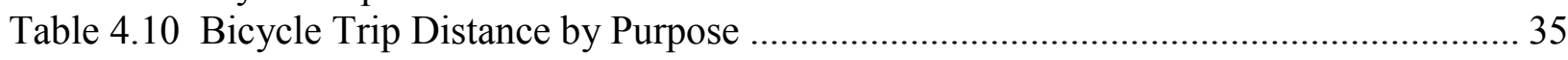

Table 4.11 Bicycle Trip Speeds by Purpose ………………………………………………..... 35

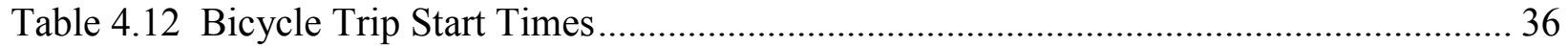

Table 4.13 Bicycle Trip Start Times, by Trip Purpose ........................................................... 37

Table 4.14 Self-reported Weather Conditions ………................................................................... 37

Table 4.15 Factors Influencing Trip Route Choice, by Trip Destination ................................... 39

Table 4.16 Factors Influencing Trip Route Choice, Trips With and Without Adults or Children

Table 4.17 Factors Influencing Trip Route Choice, by Sex .................................................... 40

Table 4.18 Factors Influencing Trip Route Choice, by Bicycling Frequency .............................. 41

Table 4.19 Factors Influencing Trip Route Choice, by Safety Attitude ...................................... 42

Table 4.20 Bicycle Travel by Facility Type ……………...................................................... 43

Table 4.21 Difference in Bicycle Travel by Facility Type, Observed vs. Shortest-Path Routes. 47

Table 4.22 Difference in Bicycle Travel by Facility Type, Observed vs. Shortest-Path Routes,

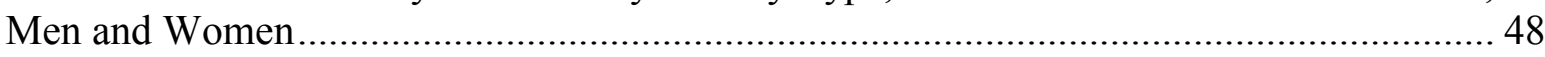

Table 4.23 Difference in Bicycle Travel by Facility Type, Observed vs. Shortest-Path Routes,

Frequent and Infrequent Bicyclists .................................................................................. 48

Table 4.24 Observed Bicycle vs. Predicted Motor Vehicle Travel Times .................................. 49 


\section{LIST OF FIGURES}

Figure 3.1 Home Locations of Participants and Bicycle Infrastructure......................................... 15

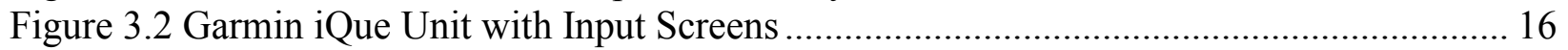

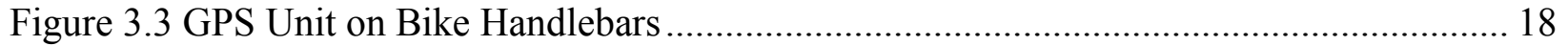

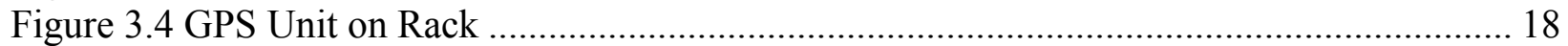

Figure 3.5 Example of Map of Bicycle Trip Presented to Participant for Feedback..................... 19

Figure 3.6 Example of Route with Spurious U-turns ............................................................... 23

Figure 3.7 Density of Recorded Bicycle Travel ....................................................................... 24

Figure 3.8 Density of Shortest-path Routes for Bicycle Trips................................................... 25

Figure 3.9 Recorded Bicycle Travel (Central Area) ……......................................................... 26

Figure 3.10 Shortest-path Routes for Bicycle Trips (Central Area) ………………………...... 27

Figure 4.1 Miles Bicycled per Day ......................................................................................... 32

Figure 4.2 Mean Number of Trips and Miles per Day, by Age .................................................. 33

Figure 4.3 Distribution of Bicycle Trip Start Times, by Hour................................................. 36

Figure 4.4 Distribution of Trips by Percent of Trip Mileage on Streets with Bike Lanes .......... 44

Figure 4.5 Distribution of Trips by Percent of Trip Mileage on Multi-use Paths ....................... 44

Figure 4.6 Median Difference (miles) between Observed and Shortest Route, by Trip Length . 45

Figure 4.7 Difference (Miles) between Observed and Shortest Path for Trips 10 miles or Less,

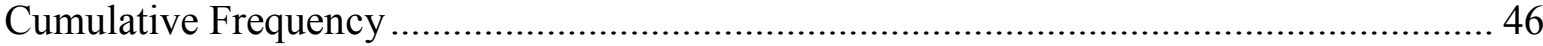

Figure 4.8 Percentage Difference between Observed and Shortest Route, by Trip Length ........ 46 Figure 4.9 Difference between Observed Bicycle and Predicted Motor Vehicle Travel Times (minutes), by Trip Distance 


\section{EXECUTIVE SUMMARY}

With rates of obesity, heart disease, and related health problems increasing in the U.S., many policy makers are looking for ways to increase physical activity in everyday life. Using a bicycle instead of a motor vehicle for a portion of everyday travel could help address these problems.

Current rates of bicycling for transportation in major urban areas in the U.S. are very low. However, over $60 \%$ of all personal trips are five miles or less in length - a reasonable distance to ride a bike - and nearly $40 \%$ are two miles or less. Moreover, bicycling is a popular form of recreation throughout the country. Given the potential for bicycling for utilitarian travel, why aren't more people cycling? There is very little research in the U.S. on bicycling. One area where data are lacking is on the effect of different types of infrastructure, such as bicycle lanes or paths, on bicycling. This research project aims to fill that data gap.

The project used global positioning system (GPS) technology to record where a sample of 164 adults in the Portland, OR, region rode their bicycles. Data was collected from March through November 2007. The participants in this study were primarily, though not exclusively, regular bicyclists who usually rode more than one day per week year round. The data presented focus on trips made exclusively on a bicycle, excluding trips where, for example, the participant took his/her bicycle on transit. This report uses data to address four primary research questions:

\section{How often, why, when, and where do cyclists ride? How does this vary based upon rider characteristics?}

- During the study, the participants made an average of 1.6 bicycle trips each day and rode an average of 6.2 miles per day. Women made about the same number of trips per day, but rode shorter distances. Trip frequency declined with age.

- The median bicycle trip distance was 2.8 miles. Exercise trips were significantly longer, with a median distance of 8.5 miles.

- The vast majority of bicycle travel recorded by participants was for utilitarian purposes. Only $5 \%$ of the trips were purely for exercise. Aside from riding back home, riding to work was the most frequent trip purpose (25\%). About $18 \%$ was for shopping, dining out, or other personal business, and 12\% was for social/recreation purposes (such as going to the movies, the gym, or visiting friends).

- Bicyclists are "trip chaining" - making multiple stops on their bicycle trips.

- When the bicyclists were riding for utilitarian purposes, they rode mainly on facilities with bicycle infrastructure. Over half $(52 \%)$ of the miles bicycled on utilitarian trips were made on facilities with bicycle infrastructure, including streets with striped bike lanes, separate paths, or bicycle boulevards. Over one-quarter $(28 \%)$ of the mileage occurred on streets (arterials or minor streets) with bike lanes. An equal share $(28 \%)$ occurred on minor streets without bike lanes. These are typically low traffic volume, residential streets. 
Therefore, only $19 \%$ of the travel was on streets that would be expected to have high volumes of motor vehicle traffic and no separate facility for a bicycle.

\section{How do cyclists' routes differ from the shortest network distance?}

- Cyclists are generally not traveling on the shortest route possible. For bicycle trips 10 miles or shorter, the median difference between the observed route and the shortest path between the same origin and destination was just under a quarter mile ( 0.24 miles). This represents about an extra 1.5 minutes of travel, given the average speed on the trips.

- Comparing the facilities used for the observed trips to the shortest route available reveals some preferences in facility type (Table 0.1). Bicyclists are going out of their way to ride on facilities with bicycle infrastructure and on low traffic streets. In particular, they rode $14 \%$ of their miles on paths, compared to $6 \%$ of the miles for the shortest paths. Many bicyclists are avoiding arterials and highways that do not have bike lanes. Those facilities represented $19 \%$ of the bicyclists' recorded miles. If they had taken the shortest path possible, $36 \%$ of their miles would be on those types of facilities. This also indicates that the major streets without bike lanes are often part of the shortest path between two points.

Table 0.1 Difference in Bicycle Travel by Facility Type, Observed vs. Shortest-Path Routes

\begin{tabular}{l|c|c|c}
\hline \multirow{2}{*}{ Facility Type } & \multicolumn{2}{|c}{$\%$ of miles } & \multirow{2}{*}{$\begin{array}{c}\text { \%o point difference } \\
\text { in share of miles } \\
\text { (observed - } \\
\text { shortest) }\end{array}$} \\
\cline { 2 - 3 } & $\begin{array}{c}\text { Observed } \\
\text { Bicycle } \\
\text { Trips }\end{array}$ & $\begin{array}{c}\text { Shortest- } \\
\text { Path } \\
\text { Routes }\end{array}$ & $-17 \%$ \\
\hline $\begin{array}{l}\text { Arterials or highways without } \\
\text { bike lanes }\end{array}$ & $19 \%$ & $36 \%$ & $+4 \%$ \\
\hline Streets with bike lanes & $28 \%$ & $24 \%$ & $+6 \%$ \\
\hline Bicycle boulevard & $10 \%$ & $4 \%$ & $+8 \%$ \\
\hline Multi-use paths & $14 \%$ & $6 \%$ & \\
\hline
\end{tabular}

\section{What factors influence cyclists' route choice decisions? How do personal attributes influence these decisions?}

- When asked about their route choices and preferences for utilitarian trips, participants placed the highest importance on minimizing distance and avoiding streets with lots of vehicle traffic. Riding on a street with a bicycle lane was usually ranked third in importance, followed by reducing waiting time at stop lights and signs. These top four preferences reflect two sometimes conflicting sets of objectives. Most utilitarian bicyclists want to minimize their travel time. That is a fundamental assumption in travel demand modeling and planning for all travelers, no matter the mode (car, transit, etc). However, depending upon the network available, the quickest route for bicyclists may not satisfy their second major set of objectives, which is related to avoiding motor vehicle traffic.

- The stated and revealed preference data comparing men and women found that women are more likely to prefer to bicycle on low traffic streets and bicycle boulevards, and less likely to prefer riding on busier streets with bike lanes. 
- Similarly, less experienced bicyclists placed higher importance on factors that make the trip easier - routes with less traffic and requiring less physical effort. They were more likely to go out of their way to use multi-use paths and less likely to divert from the shortest path to use a street with a bike lane.

\section{What is the difference in travel time between bicycling and driving?}

- For all but a handful of the bicycle trips, the estimated auto travel time was shorter. On average, the bicycle trips were 13.4 minutes longer than the estimated auto travel time. The median difference was 9.5 minutes.

- For half of the shorter trips (3 miles or less), the difference between the bicycle and auto travel time was less than five minutes.

\section{Policy Implications}

The study has several policy implications. The findings and analysis to date indicate the following:

- Bicyclists do use and value the infrastructure provided (lanes, paths, and boulevards).

- Well-connected low-traffic streets, bicycle boulevards, and separate paths may be more effective than bicycle lanes on busy streets at getting more women and new adults bicycling.

- A well-connected street network also appears to be important, both for minimizing travel distances and allowing for an efficient network of low-traffic streets and bicycle boulevards.

- While the data indicate that bicycle boulevards and paths may be more effective than bike lanes on arterials at encouraging more bicycling among groups of people who currently do not bicycle much, the importance of bike lanes should not be ignored. Over onequarter $(28 \%)$ of all of bicycle travel occurred on streets with bike lanes. The data indicate that adding bike lanes to more arterials might reduce travel times and distances, particularly for experienced bicyclists. This could increase bicycle travel.

- Finally, for many short trips (3 miles or less), the bicycle was somewhat time-competitive with the automobile - within five minutes. Shorter trips are most likely to occur in areas with a greater mix of land uses and higher network connectivity, making potential origins and destinations closer. Therefore, policies that promote these features are likely to support more bicycling for transportation.

\section{Limitations}

While this study collected more detailed information on bicycling behavior than any other studies found in the literature, there are still many limitations. One limitation is that the study was only conducted in one region. Caution must always be used when conclusions based upon data from one area are used to make recommendations for another area. In addition, the bicyclists participating in this study do not represent all bicyclists. The sample included primarily regular cyclists who bike mainly for utilitarian purposes. This makes it more difficult, though not impossible, to draw conclusions about the behavior of infrequent cyclists. Because the study was 
intended to examine revealed preferences, opinions and preference of non-cyclists are not addressed.

Finally, the GPS units presented a few limitations, including potential errors when linking the GPS point data to the network. In addition, some bicycle travel was not recorded. Based upon participant-provided information, the total number of bicycle trips may be underreported by about $8 \%$. Another potential issue is that participation in the study and carrying the GPS device could influence behavior. Survey responses indicated that this may have been a minor problem 


\section{INTRODUCTION}

With rates of obesity, heart disease, and related health problems increasing in the U.S., policy makers, health professionals, and urban planners are looking for ways to increase physical activity through changing urban form. Much of the focus is on walking. While walking is an attractive option for many reasons, bicycling offers many benefits and warrants further research.

According to the 2001 Nationwide Household Travel Survey (NHTS), over $60 \%$ of all personal trips are five miles or less in length - a reasonable distance to ride a bike - and nearly $40 \%$ are two miles or less. However, only about $14 \%$ are within a reasonable walking distance, a half mile or less. Despite the potential, only about $1 \%$ of the trips people make in the U.S. are on bicycles, and less than $5 \%$ of trips under a half mile are on bikes.

There are, however, some communities where bicycle use is much higher. Bicycle use in several European countries is over 10 times higher than the U.S., even with high standards of living and relatively high auto ownership (Pucher, Komanoff, and Schimek 1999; Pucher and Dijkstra 2003; Bassett et al. 2008). For example, 15\% of the trips in Denmark, $9 \%$ of the trips in Germany, Finland, and Sweden, and $25 \%$ of the trips in the Netherlands are made by bicycle (Bassett et al. 2008). In addition, bicycles are used more often in these countries for utilitarian purposes rather than just for recreation.

In the U.S. there are some cities, particularly college towns, with particularly high rates of cycling - 10\% and more of commute trips (Federal Highway Administration 1992). Even for large cities, cycling rates for commuting can range from nearly zero to about 3\% (Dill and Carr 2003). In addition, bicycling is a popular form of recreation throughout the country. A 2002 nationwide survey of people 16 and older found that $27 \%$ had bicycled in the past 30 days, with recreation being the most common purpose (National Highway Traffic Safety Administration and Bureau of Transportation Statistics 2003). Data from the 2001 Nationwide Household Travel Survey indicates that about half of the households in the U.S. have an adult-sized bicycle.

Given the potential for bicycling for both utilitarian travel and recreational purposes, why aren't more people cycling? There is very little research in the U.S. on bicycling. What does exist provides some general indications, but is limited in scope and often employs unreliable methods (Bureau of Transportation Statistics 2000). One area where data are lacking is on the effect of different types of infrastructure, such as bicycle lanes or paths, on bicycling. This research project aims to fill that data gap.

Specifically, the project used global positioning system (GPS) technology to record the bicycling behavior of a sample of bicyclists from the Portland, OR, region. Data were collected for one week. Comparing different types of bicyclists and comparing their bicycle routes to alternative routes can build understanding about preferences for different types of facilities. In addition, travel time is always an important factor in mode choice. Comparing bicycle travel times to auto travel times may help define the types of environments where the bicycle is a time-competitive option. 


\subsection{BACKGROUND AND RESEARCH OBJECTIVES}

\subsection{OVERVIEW OF BICYCLING BEHAVIOR}

Most traditional data sources do not provide extensive information about the levels and types of bicycling activity and where that activity occurs. One problem is that bicycling is a relatively rare activity. Nationally, only about one-half of $1 \%$ of workers regularly commuted by bicycle in 2006 (American Community Survey data retrieved from factfinder.census.gov). Therefore, random surveys, even those with large samples, may not capture much bicycling activity. A commonly used source of more detailed transportation data is a travel survey. These surveys typically collect detailed travel activity information for a single day from a population sample for a region or state, or nationally.

In the U.S., the 2001 National Household Travel Survey (NHTS) found that only 1\% of all trips were made on bikes. Only about $30 \%$ of adults said they had ridden a bike in the past week (data retrieved from nhts.ornl.gov). That survey collected data on fewer than 1,000 bike trips by adults nationally. Moreover, traditional travel surveys do not include questions about people's routes or facility preferences. Health-related surveys, such as the Behavioral Risk Factor Surveillance System (BRFSS), typically have larger samples than travel surveys. However, until 2001 the questions on physical activity focused on leisure-time activity, thus missing bicycling for transportation (Centers for Disease Control and Prevention 2003).

Some surveys do have limited data on the frequency, duration, and location of cycling. A random phone survey of adults found that only $27 \%$ of Americans age 16 or older rode a bicycle at least once during the summer of 2002 (National Highway Traffic Safety Administration and Bureau of Transportation Statistics 2003). On the most recent day that those respondents rode, they made an average of 1.6 bicycle trips, defined as going from starting point to a specific destination. About half of the trips were for recreation or exercise. Of the trips reported, only $5.2 \%$ were made mostly in bicycle lanes and $13.1 \%$ were mostly on paths or trails. Because the question asked where the person "mostly" rode for that trip, it is impossible to get an accurate estimate of where all of the bicycle travel occurred. In most U.S. cities, it would be rare that a person could ride for a majority of their trip on a road with a bike lane, particularly for utilitarian trips where the origin and destination help define the available infrastructure to a large extent.

A non-random survey of nearly 2,500 U.S. cyclists found a median one-way commute time of 20 minutes (Moritz 1998). According to the respondents, nearly one-quarter of their commute occurred in bike lanes or paths. Using American Housing Survey data, Plaut (2005) found that regular bicycle commuters traveled an average of 2.54 miles and 15.3 minutes to work.

Assuming people bicycle in both directions, this implies that the average bicycle commuter bikes for at least 30 minutes each day. One limitation of such self-reported travel data, however, is that people often round off their travel times to the nearest five minute increment and overestimate travel times (Murakami and Wagner 1999). 
If communities hope to significantly increase rates of cycling for travel, the mode must become more attractive to groups who currently do not bike regularly. For example, U.S. studies consistently find that women are less likely to bicycle for commuting or other transportation purposes than men (National Highway Traffic Safety Administration and Bureau of Transportation Statistics 2003; Plaut 2005; Dill and Voros 2007; Shafizadeh and Niemeier 1997; Vernez-Moudon et al. 2005). This may be because women are more concerned about safety, particularly from vehicle traffic (Health Canada 1998; Garrard, Rose, and Lo 2008). In the U.S., cycling rates also decline with age (National Highway Traffic Safety Administration and Bureau of Transportation Statistics 2003).

There are many factors that influence a person's decision to bicycle (Federal Highway Administration 1992). These factors can be categorized as (1) objective or environmental; (2) subjective; and (3) demographic. Environmental factors include climate, topography, land use, and infrastructure. Infrastructure includes the bicycle facility network (lanes, paths, shared roads, etc.), bicycle parking, and support facilities (e.g., showers at work sites and racks on buses), as well as the infrastructure provided for other, competing modes.

Objective measures of environmental factors might commonly be called "reality" or the "truth." For example, with geographic information systems (GIS) researchers can measure how many miles of bike lanes are within a certain distance of a person's home. That is an objective measure. However, most individuals would not know how many miles of bike lanes are within a quarter mile of their home. They may base their decision on their subjective observation or opinion about the presence of bike lanes near their home. Therefore, the category of subjective factors includes individuals' perceptions of the physical environment. A subjective measure of the environment would be the answer to the question "are there bike lanes near your home?" It also includes other subjective factors, such as an individual's attitudes about bicycling, safety, physical activity, etc.

Finally, demographic factors include things such as age, income, gender, and health status. All three of these groups of factors undoubtedly have direct and indirect influence on bicycling behavior. While the amount of research on bicycling appears to be increasing, there is limited objective evidence as to how these factors influence the decision to bicycle. There is even less evidence regarding cyclists' route choice decisions. This research focuses on the role of infrastructure, primarily objective measures of infrastructure. However, other environmental, subjective, and demographic factors play a role and are included in the analysis.

\subsection{THE INFLUENCE OF INFRASTRUCTURE ON BICYCLING BEHAVIOR}

This section reviews existing research on how infrastructure, measured both objectively and subjectively, influences bicycling behavior. Two behavioral decisions are of particular importance: (1) the decision of whether or not to ride a bicycle for a particular purpose and (2) once the decision is made to ride, the choice of what route to take. 


\subsubsection{Decisions on Whether or Not to Bicycle}

Several studies support the notion that providing bicycle infrastructure, particularly lanes and paths, can increase bicycle use. These studies can generally be broken into two categories, those that use revealed preference data (what people actually do) and those using stated preference data (what people say they would do, given a situation).

Revealed preference studies rely on travel behavior data, such as the percent of people commuting by bicycle. Several researchers have conducted case studies of U.S. cities with high rates of bicycling, often making the case that infrastructure played a key role (Pucher, Komanoff, and Schimek 1999; Buehler and Handy 2008; Xing, Handy, and Buehler 2008). Similar cases have been made for cities in Canada and Europe (Pucher and Dijkstra 2003, 2000; Pucher and Buehler 2006).

Other revealed preference studies compare and analyze a larger number of cases, relying on aggregate data, often from the U.S. Census, at the county, city, or census-tract level. A study of large cities in the U.S. found that higher levels of bicycle commuting were associated with higher densities of bicycle lanes (Dill and Carr 2003). An earlier study of mainly small cities came to a similar conclusion (Nelson and Allen 1997). At a smaller scale, a study of Portland, OR, found a positive correlation between bicycle commuting (from Census data) and bike lanes at the census-tract level (LeClerc 2002). However, using disaggregate data, other studies (using original survey data from random samples of individuals) have not found a link between the provision of bike lanes and levels of bicycling for transportation (Vernez-Moudon et al. 2005; Dill and Voros 2007).

The stated preference studies generally ask people questions about what might influence whether they bicycle or not. For example, the National Survey of Pedestrian and Bicyclist Attitudes and Behaviors asked respondents, regardless of whether they bicycled recently or not, for recommendations on what changes they would like to see in their community. Nearly half (47\%) stated that they did want changes and $73 \%$ of those listed infrastructure, including bike lanes, paths, racks, signals, etc. The National Bicycling and Walking Study (NBWS) cites several older surveys about why people do or do not bicycle (Federal Highway Administration 1992). For example, from $12 \%$ to $17 \%$ of the active bicyclists surveyed in Boston, MA, Gainesville, FL, and Portland, OR, cited the lack of facilities as a reason for not commuting by bicycle. A national poll conducted for Bicycling magazine in 1991 found that "safe bike lanes" could encourage 20\% of adults to ride to work, the top rated improvement. The NBWS includes many other surveys with similar findings.

\subsubsection{Route Choice Decisions}

Studies that focus on cyclists' route choice decisions also can be divided based upon the use of revealed or stated preference methods. The more useful stated preference studies present respondents with two options, usually trading off a supposedly higher quality facility (e.g., a dedicated bike lane) with a longer travel time. This more accurately reflects the reality that such facilities will likely be spaced much further apart than roadways. Using this technique, at least three studies have found that cyclists value bike facilities (Tilahun, Levinson, and Krizek 2007; 
Stinson and Bhat 2003; Hunt and Abraham 2007; Krizek 2006) ${ }^{1}$. Krizek (2006) found that bicycle commuters prefer bike lanes on streets over off-street trails. Stinson and Bhat (2003) found that travel time was the most important factor for bicycle commuters.

Other important factors included bike lanes or paths, the amount of automobile traffic, and pavement or surface quality. Hunt and Abraham (2007) found that one minute of bicycling on a street with motor vehicles was "as onerous" as 4.1 minutes of bicycling on a bike lane or 2.8 minutes of bicycling on a separate path. These findings indicate that bicyclists will go out of their way to use lanes or paths, sacrificing some amount of time. The sensitivity varied by experience; more experienced cyclists were less willing to sacrifice time to use the special bike facilities. Tilahun et al (2007) found that women were even more likely than men to choose facilities perceived as safer (e.g., a slower path instead of a faster bike lane), though the difference was not quite significant.

Revealed preference studies attempt to associate actual route choices with the presence of specific bicycle infrastructure. One revealed preference method compares the shortest distance route to the route actually used by a cyclist. The amount of extra time the cyclist spends to use a bike lane or path that is not on the most direct route demonstrates the value of that facility for that person.

Several such studies have found that cyclists will take a longer route to use bicycle facilities, such as lanes or paths (Shafizadeh and Niemeier 1997; Howard and Burns 2001). In an intercept survey of commuting cyclists at four locations in Seattle, Shafizadeh and Niemeier (1997) concluded that some cyclists may travel further distances on separate paths, compared to cycling on streets with vehicles. Krizek, El-Geneidy, and Thompson (2007) found that bicyclists riding on a trail in Minneapolis, MN, were willing to travel, on average, $67 \%$ further to use the trail.

In contrast, a study in Guelph, Ontario, Canada, found that bicycle commuters diverted very little from the shortest path. Moreover, the commuters appeared to prefer not to ride on paths or trails. While paths made up $7 \%$ of the length of the network available to cyclists, commuters used them for only $5 \%$ of their travel. There were no differences in route preferences by gender or age (Aultman-Hall, Hall, and Baetz 1998).

One possible explanation for the contrast in findings is that most of the bicycle travel in the Minneapolis study was for recreation, not commuting or other utilitarian purposes. This is consistent with a national survey that asked what changes bicyclists would like in their community. A higher share of frequent cyclists preferred more bike lanes rather than paths. Infrequent cyclists were more likely to want more bike paths rather than lanes (Bureau of Transportation Statistics 2004).

A less-used revealed preference method relies upon observations. Counts of cyclists in Melbourne, Australia, found that women preferred facilities that maximized the separation between them and motor vehicles, with the strongest preference for off-road paths, followed by bike lanes (Garrard, Rose, and Lo 2008).

\footnotetext{
${ }^{1}$ Results from the three studies have been published in the four separate articles cited.
} 
Most of the existing revealed preference studies on route choice ask bicyclists to remember their route for a specific trip using a paper map or other mechanism. For example, McDonald and Burns (2001) asked bicycle commuters to document their most recent commuting route, which was then analyzed using GIS. Aultman-Hall, Hall, and Baetz (1998) used a survey where respondents drew their routes on a map. They indicated some problems with people misinterpreting the map, resulting in a few impossible routes that had to be discarded. The authors also noted that the survey instrument did not collect directional information, thus limiting accurate analysis of things such as elevation change (i.e., whether the cyclist was going uphill or downhill). In addition, this method usually limits data collection to one trip.

One limitation of some of the existing studies is that the participants are often regular and enthusiastic bicyclists. For example, Howard and Burns (2001) focused on "dedicated commuting cyclists" who were far more likely to be men aged 25-44. Stinson and Bhat's study was conducted on the Internet using a self-selected group of respondents who were "mostly avid bicyclists." If one objective is to increase the share of people cycling for transportation, a more diverse group of travelers must be attracted to the mode.

\subsection{RESEARCH OBJECTIVES}

The research presented in this report is part of a larger project originally funded by the Active Living Research program of the Robert Wood Johnson Foundation. The original objectives of the project were to: (1) examine the relationship between urban form and people's decision to bicycle; (2) examine other intervening factors influencing the decision to bicycle, such as weather, topography, attitudes and perceptions, and socio-demographics; and (3) test the use of readily available technology (personal digital assistants with GPS) to objectively measure physical activity of bicyclists. That project first included a phone survey of Portland-area residents about bicycling behavior, conducted in 2005. Results from the survey are described in Dill and Voros (2007).

The second part of the project, which received supplemental funding from OTREC, involved bicycle riders carrying a GPS unit to record their bicycle trips and routes. The research presented here focuses on the GPS data collection and analysis. In particular, the following questions are addressed:

- How often, why, when, and where do cyclists ride? How does this vary based upon rider characteristics?

- How do cyclists' routes differ from the shortest network distance?

- What factors influence cyclists' route choice decisions? How do personal attributes, such as cycling with a child or the age or gender of the cyclist, influence these decisions?

- What is the difference in travel time between bicycling and driving? 


\subsection{METHODOLOGY}

\subsection{SETTING}

This study took place in the Portland, OR, metropolitan region. The region's population is about 1.6 million, with over one-third living within Portland. The City of Portland has received attention for its commitment to providing bicycle infrastructure and other supportive policies, including being named by Bicycling magazine as the best city for bicycling in the country and by the League of American Bicyclists as one of only two platinum-level bicycle-friendly cities in the U.S.

The city has a relatively high number of bike lanes compared with other large U.S. cities (Dill and Carr 2003). Rates of bicycle commuting are higher in the region than most comparably sized regions (Dill 2007). Still, only about $1.2 \%$ of the region's workers and $4.2 \%$ of the workers within Portland regularly commute by bicycle (American Community Survey data retrieved from factfinder.census.gov).

Bicycle infrastructure in the region includes about 550 miles of bike lanes on streets, 130 miles of separate bike paths, and 30 miles of "bicycle boulevards." Bicycle boulevards are low-traffic residential streets, usually running parallel to a major road, that use traffic calming features to give priority to bicycles over motor vehicles. For example, barriers at some intersections force cars to turn while bikes can continue on a through path. Traffic signals allow bikes traveling on the boulevard to cross busy streets safely. The routes are signed and usually connect with other bicycle infrastructure, including bike lanes on arterial streets and bridge crossings.

\subsection{PARTICIPANT RECRUITMENT AND SELECTION}

The study collected GPS data from 166 bicyclists from March to November 2007. The participants were recruited by two primary methods. First, an earlier phase of the project included a random phone survey of adults in the region (Dill and Voros, 2007). All cyclists identified through that survey who agreed to be contacted again (158) were invited to participate. However, only 12 of those 158 phone survey respondents agreed to participate and only nine ended up collecting GPS data.

Second, a variety of methods were used to solicit participants from the general public. The most successful method involved two articles in the region's major daily newspaper (The Oregonian) that described the project. The first article appeared January 14, 2007, and briefly explained the study ("Professor wants to follow you on your bicycle," page B8). That article was circulated on numerous email lists and websites, which generated over 300 inquiries from potential participants. On August 15, 2007, a second article appeared describing the study in more detail. By that time, GPS data had been collected from many cyclists, though primarily very avid, regular cyclists. Therefore, the story highlighted the need for less-frequent cyclists to participate. The headline read "Secret habits of timid cyclists studied," (page C1). At the same time, the 
project distributed flyers at bike shops and the annual Bridge Pedal event specifically targeting less-frequent cyclists. Over 100 people responded to this phase of advertising.

In both phases, each person was invited to complete an online version of the phone survey, which collected information about general bicycling behavior and experiences, attitudes about various mobility options, and demographics. A total of 386 people completed the online survey, and the GPS participants were selected using a stratified random sampling method. The objective was to get a range of types of cyclist (frequent vs. infrequent), home location ( Portland vs. the remainder of the region), age, and gender. The sample was not intended to exactly represent the general cycling public. If the sample had done so, there would likely be too few of certain types of cyclists to examine their behavior separately.

A total of 193 people were invited to participate in the GPS portion of the study. Of these, 166 completed the study. The others dropped out for various reasons. Many of them did not respond to numerous contacts after the original invitation. Others had injuries, travel plans, or other events that precluded their participation. The home locations of the participants are shown in Figure 2.1, along with the bicycle infrastructure in the region. ${ }^{2}$ While efforts were made to recruit participants in all parts of the region, there are very few participants in the eastern section..

All survey instruments and data collection methods were reviewed and approved by the Human Subjects Research Review Committee at Portland State University.

\footnotetext{
${ }^{2}$ All but two participants, who lived outside the urban growth boundary, are shown on the figure.
} 


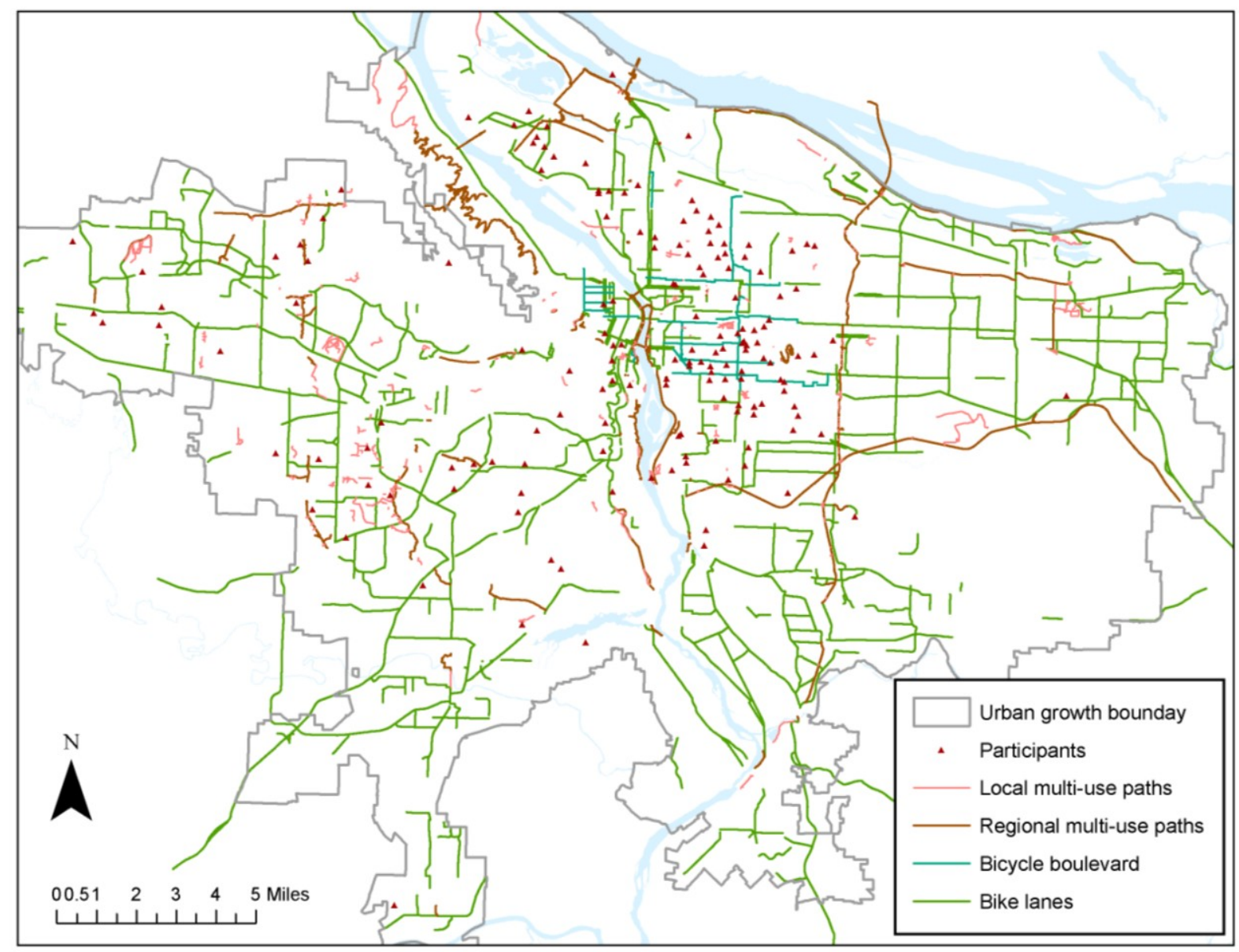

Figure 2.1 Home Locations of Participants and Bicycle Infrastructure

\subsection{DATA COLLECTION}

Respondents were assigned a project team member, contacted via email and asked to confirm that they would like to participate. The project team member then scheduled an initial meeting in which the participant received the GPS unit and training on its proper use. The unit was a Garmin iQue, a personal digital assistant with GPS. The units were specially programmed using the Palm operating system to collect additional data (Figure 2.2).

At the start of each bike trip, the participant tapped on the screen to enter their trip destination category (e.g., work, school, shopping, exercise, etc.) and the weather, wind, and temperature. The options for trip destinations are shown in Table 2.1, along with the explanation provided to participants in written materials. Weather options included sunny/clear; cloudy, no rain; cloudy, may rain; light rain; heavy rain; and fog. Wind options included no wind, light wind and heavy wind. Temperature options included moderate, hot, and cold. The participant was also asked to electronically check a box if they were walking with their bike or taking their bicycle on transit as part of their bicycle trip. 

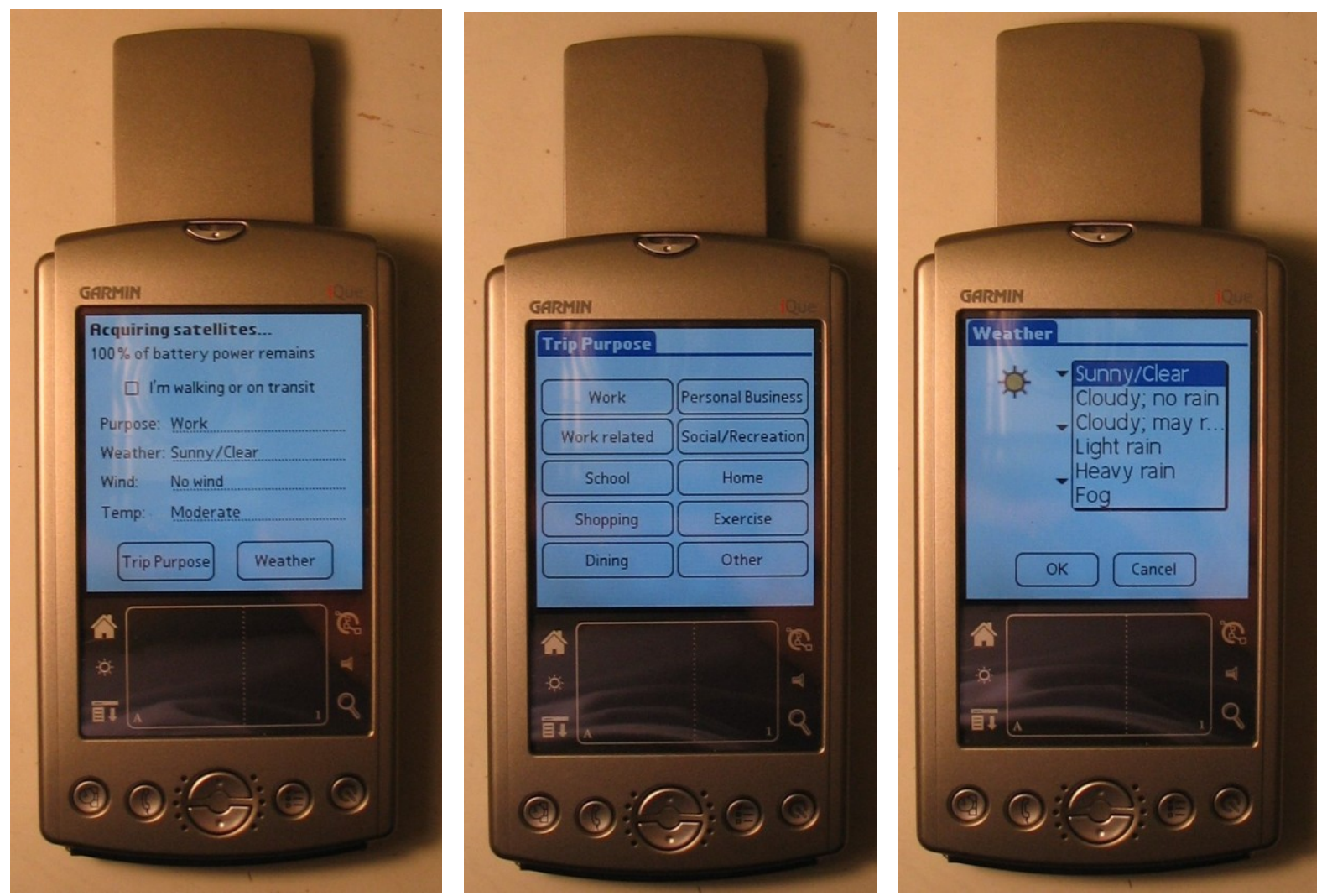

Figure 2.2 Garmin iQue Unit with Input Screens 
Table 2.1 Trip Purposes and Examples Provided to Participant

\begin{tabular}{|c|c|}
\hline Purpose & Explanation/Examples \\
\hline Work & Going to work, e.g. commuting \\
\hline Work-related & $\begin{array}{l}\text { Going somewhere, besides your normal workplace, but for work purposes. An } \\
\text { example would be a business or client meeting. }\end{array}$ \\
\hline School & $\begin{array}{l}\text { Going to school as a student. If you work at a school the trip purpose would be } \\
\text { "work." }\end{array}$ \\
\hline Shopping & Going someplace to buy goods, such as groceries, clothing, or books. \\
\hline Dining & $\begin{array}{l}\text { Going someplace to eat and/or drink, including restaurants and cafes. If you take the } \\
\text { food to go, as long as it is prepared to immediately eat/drink, the purpose would still } \\
\text { be dining. }\end{array}$ \\
\hline $\begin{array}{l}\text { Personal } \\
\text { Business }\end{array}$ & $\begin{array}{l}\text { Other types of "errands" besides shopping or dining, including dry cleaning, dentist, } \\
\text { doctor, bank, haircuts, non-work meetings (e.g. neighborhood association). }\end{array}$ \\
\hline $\begin{array}{l}\text { Social/ } \\
\text { Recreation }\end{array}$ & $\begin{array}{l}\text { Examples include movies, museums, theater, a park, the gym, playing soccer or } \\
\text { other activities, attending sporting events, visiting friends, library, etc. Hanging out } \\
\text { at a bar, if the primary purpose is to be social, would be included here. }\end{array}$ \\
\hline Home & Use this when you are returning home from someplace. \\
\hline Exercise & $\begin{array}{l}\text { Use this trip purpose if the primary reason for your bicycle trip is to get exercise, } \\
\text { without any destination for another purpose. There is a difference between trip } \\
\text { "purpose" and your motivation for bicycling. For example, if you are riding your } \\
\text { bike to work, but your main motivation for riding the bike rather than driving is } \\
\text { exercise, the trip purpose is still "work." }\end{array}$ \\
\hline Other & $\begin{array}{l}\text { Anything that isn't clearly included above. Examples include going to church or } \\
\text { transporting someone (e.g., taking your child to school). }\end{array}$ \\
\hline
\end{tabular}

Once on and within view of three or more satellites, the unit recorded its position ("point") and speed every three seconds. To minimize any effects the units might have on cycling behavior, the unit only ever displayed the trip destination and weather input options, whether GPS data was being recorded, and the remaining battery charge. No maps were displayed. The participant was not allowed to use the other software features built into the iQue. The data and program were stored on a memory card in the unit.

The team member fit the GPS unit to the participant's bicycle with an appropriate mounting system. The wide variety of bicycle types and configurations and the necessity to keep the GPS unit antenna uncovered meant that many attachment methods were used. The most common methods were to place the unit on the bike's handlebars using a special bracket (Figure 2.3), on a back rack provided by the research project (Figure 2.4), or on the participant's existing rack using a bungee cord. Plastic sleeves protected the units from rain and dirt. 


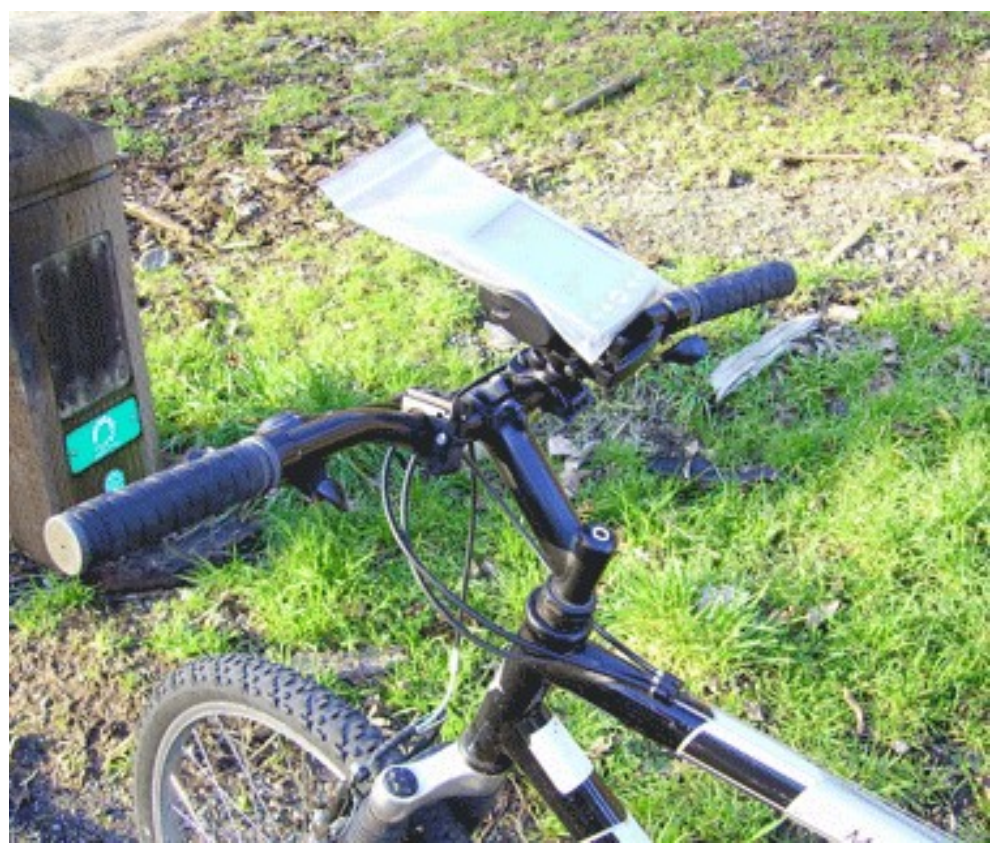

Figure 2.3 GPS Unit on Bike Handlebars

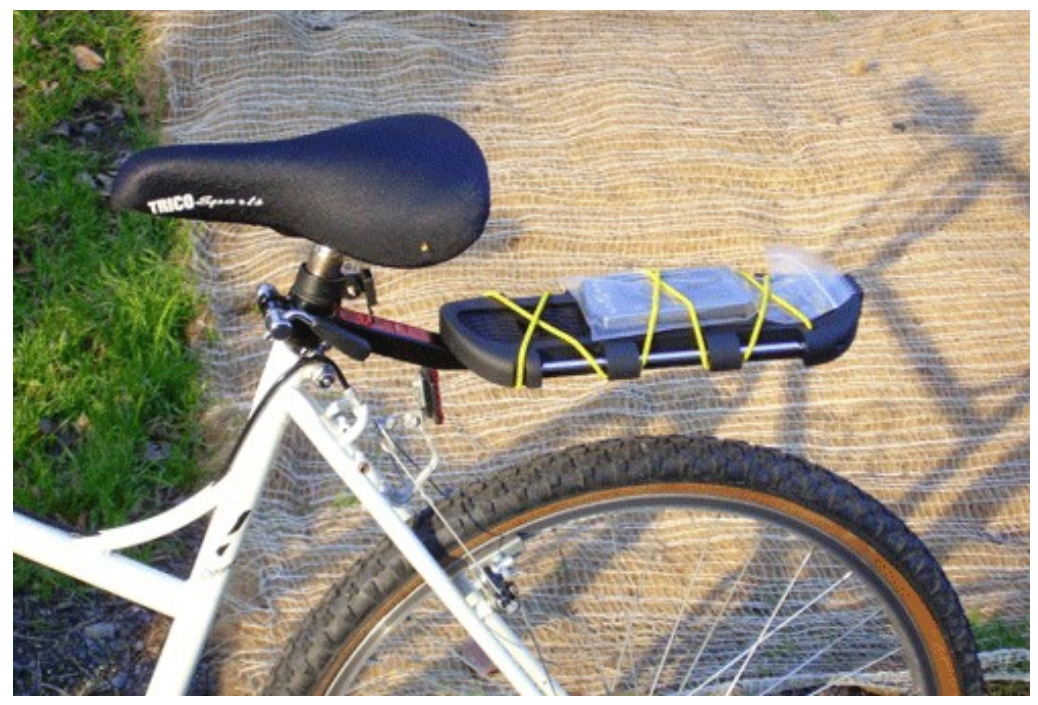

Figure 2.4 GPS Unit on Rack

Each participant was asked to carry the unit for at least seven days. The actual days each participant had the unit varied depending on availability and meeting times with the assigned project team member. The assigned team member contacted the participant during this time to check in and troubleshoot any problems with the GPS unit.

At the end of the test period, a second meeting was set to retrieve the unit. The project team member then downloaded the GPS data as a comma-separated text file to be used in the GIS analysis. The raw data was processed using Network Analyst and specific scripts developed by the project team. After this step another mapping extension was using to separate GPS data into 
separate trips associated with the street/bikeway network (described more below). This step created an individual map for each trip taken by the participant (see Figure $\mathbf{2 . 5}$ for an example). These maps were then uploaded to a project website. Each participant was given a unique login and password to access their maps.

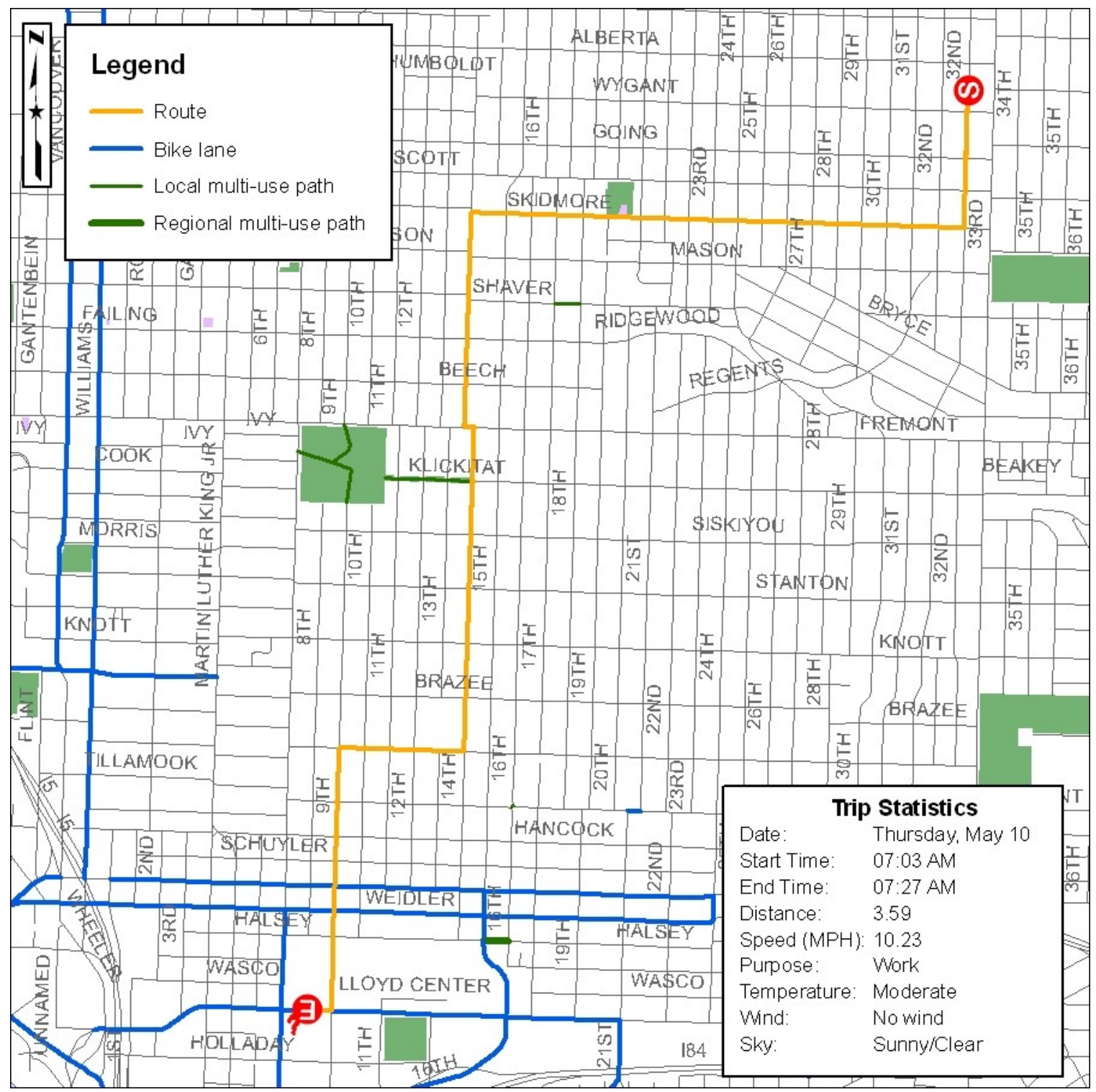

Figure 2.5 Example of Map of Bicycle Trip Presented to Participant for Feedback

For each trip and map, the participant was asked about the accuracy of the data collected, including whether the start, end, route, and trip purpose were correct. If not, they were asked to provide information so that the data could be corrected. For each trip they were also asked a series of questions:

Were any of the following situations applicable for this trip?

Another adult was riding their bike with me

A child was riding his/her bike with me 
A child was on my bike, in a trailer or seat

I was pulling a trailer, without a child

Other unique situation (please explain)

How important are the following factors in choosing this route?

Scale of 1 (not at all important) to 5 (very important)

Minimizing the total distance (e.g., most direct route)

Riding in a bike lane

Riding on an off-street bike trail or path

Riding on signed bike routes

Avoiding streets with lots of vehicle traffic

Avoiding hills

Reducing the wait time due to stop signs/lights

Other

Did you have a car or other motorized vehicle available to drive for this trip, instead of riding your bicycle?

Not applicable, trip was for exercise

No

Yes

If yes, why did you choose to ride your bike instead of driving the vehicle? (Check all that apply)

To save money (e.g., on gas or parking)

Riding my bike is faster

For exercise, health, or pleasure

To reduce my impact on the environment (e.g., pollution)

Good weather

I don't have a valid drivers license

Someone else in my household needed the car

Other (please specify)

After the maps for each trip, the participant was asked the following set of questions:

Did you make any other bike trips while you had the PDA/GPS device that were not shown?

No

Don't Know

Yes

If yes, about how many trips were not recorded with the GPS device?

(Enter a number)

What were the reasons the trips were not recorded?

I forgot to take the GPS device with me

I didn't want to take the GPS device with me

I had the device with me and turned on, but the trip was not listed 
The batteries were dead

Other (please specify)

How does the number of bicycle trips recorded compare to the number you would normally make at this time of year?

I made about the same number of bicycle trips

I made more bicycle trips

I made fewer bicycle trips

If you made more or fewer trips, please explain why.

Did your bicycle trips differ in any other way from what you would normally do this time of year?

No

Yes

If yes, please describe how your travel differed.

Did having the PDA/GPS device change your bicycle behavior in any way?

No

Don't Know

Yes

If yes, please describe how.

Once the participant completed the survey involving the maps, they were sent a letter thanking them for their participation along with a $\$ 40$ gift card to New Seasons (a grocery store), Powell's Books, Fred Meyer, or Starbucks. Participants had earlier indicated their gift card choice. Of the 166 participants that used the GPS unit, bicycle trip data were collected from 164. One participant did not ride his/her bike during the time period. The other participant's unit failed multiple times.

\subsection{DATA PROCESSING}

When turned on with the antenna up and in view of satellites, the unit recorded the cyclist's latitude and longitude every 3 seconds. The unit stopped recording if there were no satellite signals or no change in position was recorded for more than 30 seconds. Recording restarted if a new position was detected. Because the GPS devise would record relatively small movements, this feature usually did not result in the unit not recording if the bicyclist was, for example, stopped at a stop light.

These data (a series of points) were transferred from the memory cards in the GPS units to a computer after the unit was returned. Each time the participant turned the unit on, a new trip log began. However, participants did not always turn the unit off at the end of a trip. In such cases, the next trip was appended to the previous trip, with a time gap between. If the gap was more than five minutes, the log was split into two trips at that point. The data were then transformed into lines fitting the regional street network using a set of scripts utilizing ArcGIS Network Analyst commands. The original street network data was from the Metro Regional Land 
Information System (RLIS) and included both streets and off-street paths. Metro is the transportation and land-use planning agency for the Portland region. The research team was able to process and use the data from 162 of the 164 participants with GPS data.

Based upon the responses from the participants after viewing their trip maps, the research team manually corrected any route errors they identified so that the recorded route would fit the participants' actual paths. This process often involved adding some links to the digital street network. When appropriate, links were added to the Metro network based upon the GPS travel recorded. For example, participants may have travelled on paths through parks or on other facilities not available to motor vehicles. Not all of these facilities were in the original Metro data. The new links were confirmed using aerial photos or direct observation. Once the GPSbased routes were linked to the network, it was possible to calculate the mileage by facility type. Some trips were deleted altogether; these were cases where the participant indicated that the bike was on or in their vehicle for the entire trip.

Once the trip and network data was cleaned, summary statistics were calculated for the trip's start and endpoints, speed, purpose and weather conditions. Each trip was separated into its component segments ("traversals") on the street network, in order to identify how long the cyclists had ridden on each type of road facility (arterials, minor streets, bike boulevards, paths, etc.), and how much elevation change had taken place over the course of their routes. Elevation change was calculated using a USGS Digital Elevation Model (DEM) of the Portland region with a $10 \mathrm{~m}$ spatial resolution. For each trip, the DEM was used to estimate the altitude of the start and end point of each traversal. Total altitude gains and losses were cumulated separately, as well as the total aggregate elevation change.

Due to the inaccuracy of the GPS points, a large number of points had been mistakenly located on segments adjacent to cyclists' real path. For example, a GPS point may be several feet from the centerline of a street. If that happens near an intersection, the point may "snap" to the crossstreet rather than the road the person was riding on. This resulted in many very short U-turns down cross-streets that made some participants' routes appear longer than they truly were.

Two steps were taken to minimize this. First, the scripts used to create the routes from the original GPS data were based not upon every point, but on points that indicated changes in direction or similar important junctures. Some such U-turns would still remain, however, as shown in Figure 2.6. Identifying "real" and "spurious" U-turns was a difficult process, since a cyclist could very well make a wrong turn and then turn back or intentionally travel a short distance down a side street. U-turns were identified as sets of two consecutive traversal segments traveling on the same network segment but in opposite directions (implying that the endpoint of the first segment was where the U-turn happened).

In all cases where both segments were shorter than 50 feet, or 1/4 of a standard Portland block, it was assumed the U-turn was very likely to have been recorded due to instrument error and it was removed from the final traversal dataset. This eliminated about $70 \%$ of the U-turns. However, these segments only covered 90 miles, about $1 \%$ of the total of 8,515 miles of travel. Therefore, a potentially significant source of error was eliminated, while potentially removing only a small amount of "real" data. 


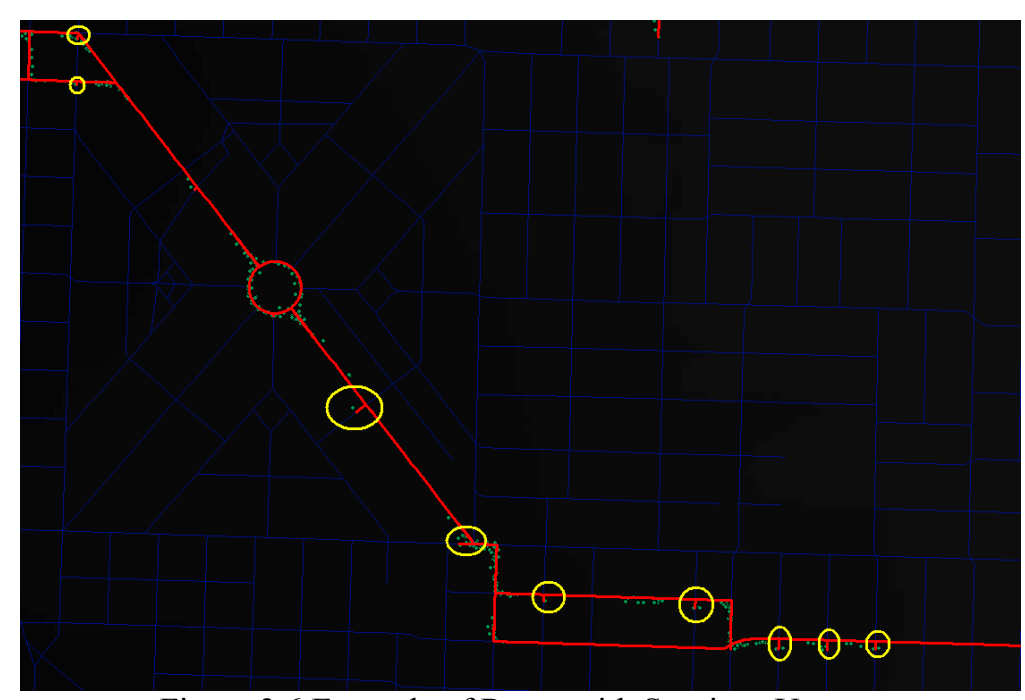

Figure 2.6 Example of Route with Spurious U-turns

In the end, this process yielded a dataset including 1,953 trips. Of those, 1,778 were made entirely on bicycle; for 175 trips the participant indicated that a portion was made with the bicycle on transit or another vehicle or by walking with the bicycle. The distribution of the trips made entirely on a bicycle, totaling over 8,400 miles, is shown in Figure 2.7. The bicycle travel covered nearly all parts of the Portland region with roads, with a heavier emphasis on the more bike-friendly areas near downtown and on the inner eastside of Portland.

\subsection{SHORTEST PATHS}

One objective of the project was to compare the cyclist's route to an alternative route based upon the shortest distance between the origin and destination. For this analysis, only trips made entirely on a bicycle were included. These shortest path routes were generated using only the start and endpoints of the recorded trips and solving for shortest distance on the network using ArcGIS Network Analyst. The research team succeeded in obtaining 1,775 routes in this manner, and the total distance traveled in this shorted path dataset was only 4,997 miles of travel.

However, it should be noted that some of the difference in miles traveled may be due to recreational exercise trips where the start and endpoints may only be a few feet apart. Figure 2.7 shows the density of actual bicycle travel for the region. Figure 2.8 illustrates the regional pattern for shortest-distance trips. The relative absence of trips outside the UGB shows that many "loop" trips were longer trips taken toward the fringes of the metro area. It also shows slightly different patterns of travel in a shortest-distance scenario, with trips more concentrated in central areas and along main roads. For the analysis comparing the shortest path to the actual bike route, trips that were made solely for exercise purpose, that were part of an organized group ride ${ }^{3}$, or that started and ended within 200 feet were not included.

Figure 2.9 and Figure 2.10 show the actual travel and shortest path routes, respectively, for the central area.

\footnotetext{
${ }^{3}$ Organized ride was not one of the categories participants could indicate on the unit. However, in the follow-up survey, a handful of participants indicated that the trip was an organized ride or tour.
} 


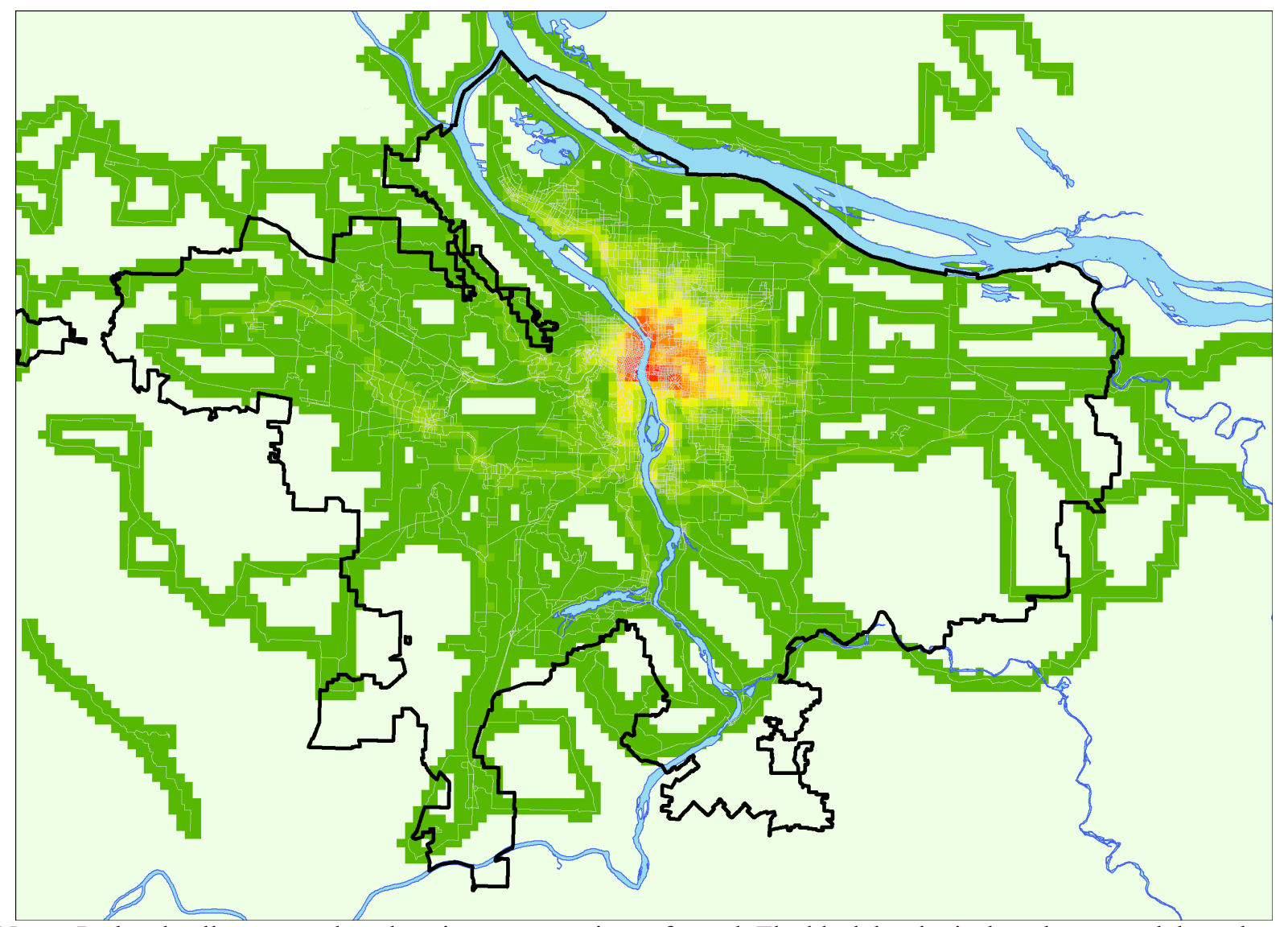

Notes: Red and yellow areas show heavier concentrations of travel. The black border is the urban growth boundary.

Figure 2.7 Density of Recorded Bicycle Travel 


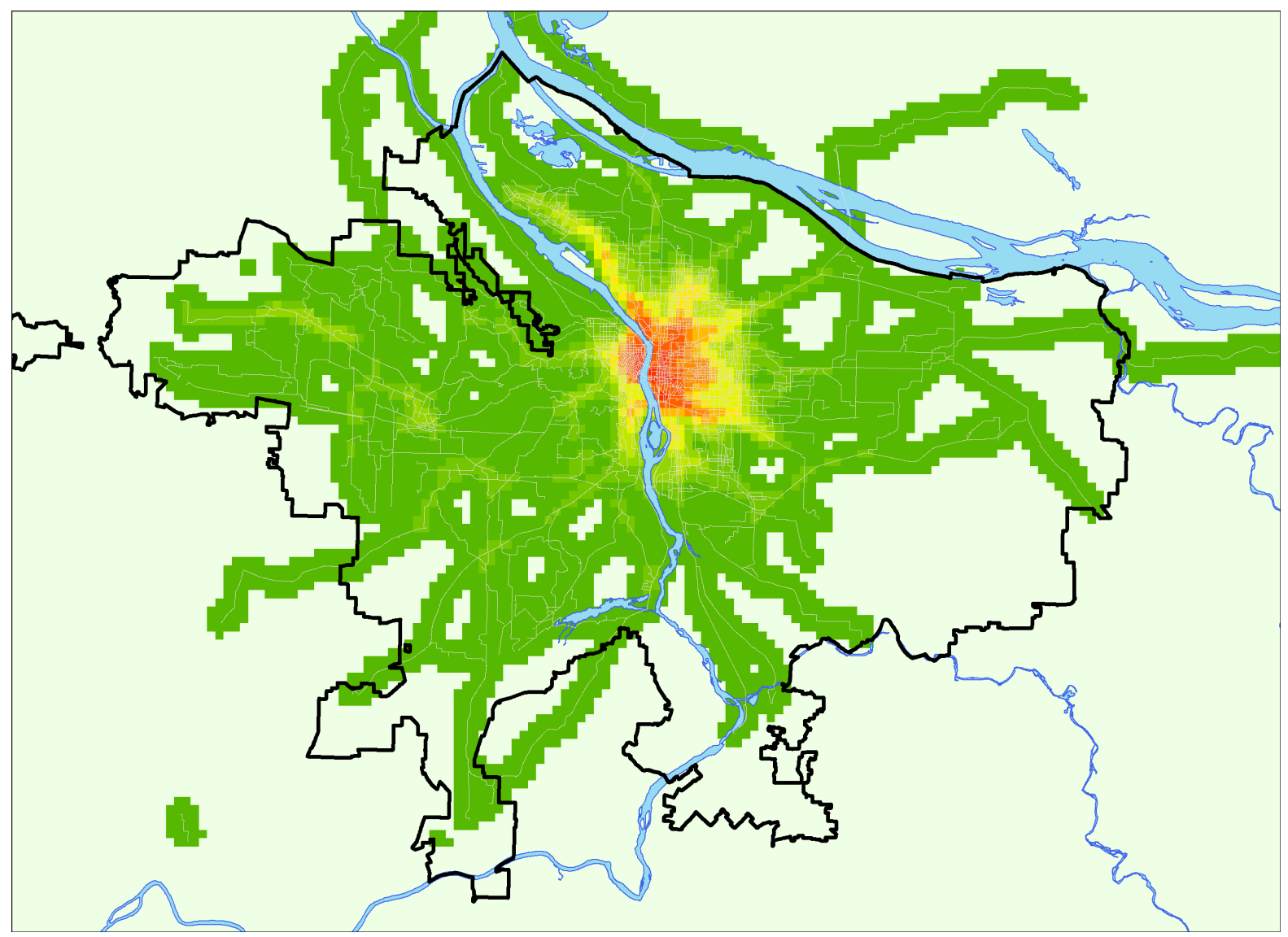

Figure 2.8 Density of Shortest-path Routes for Bicycle Trips 


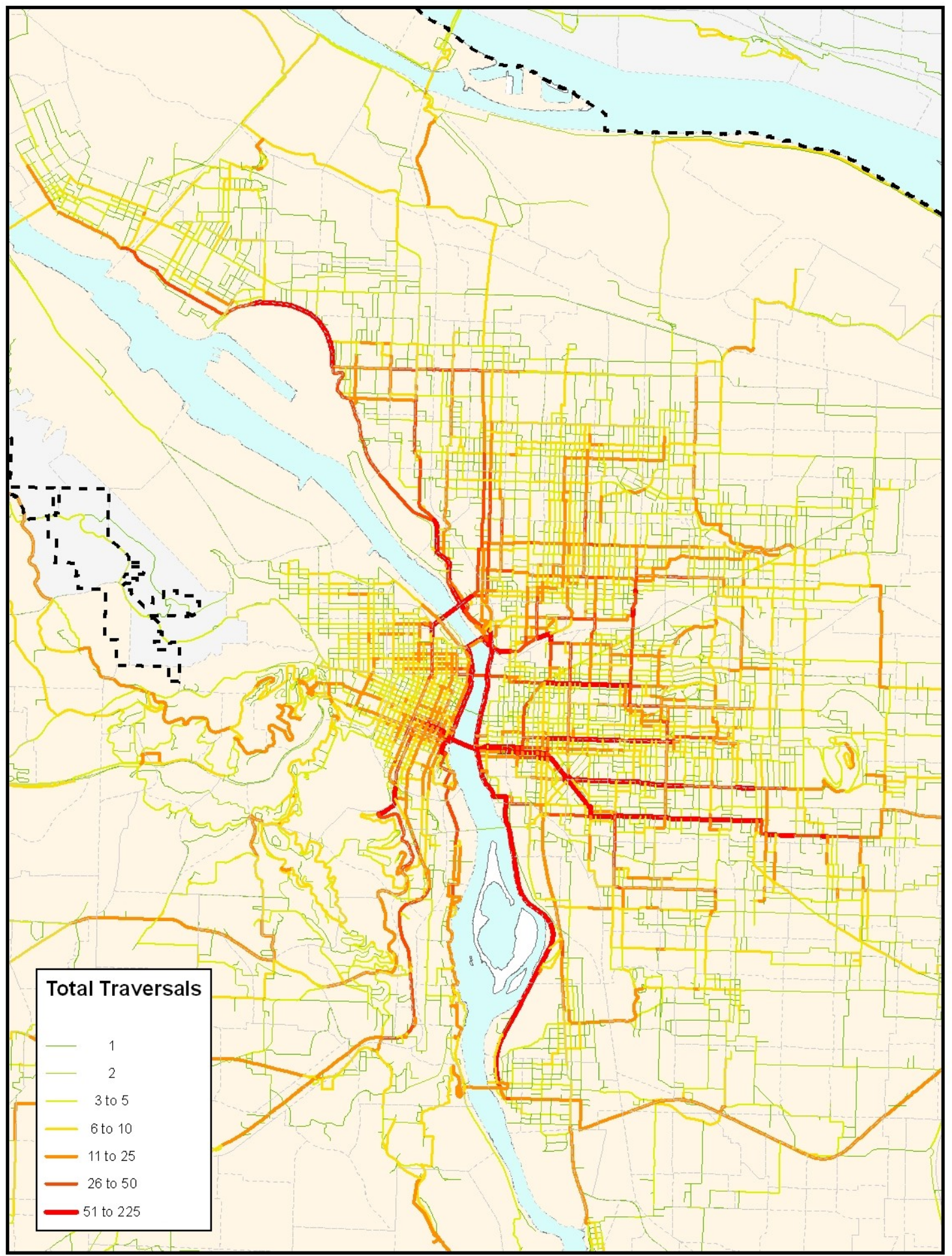

Figure 2.9 Recorded Bicycle Travel (Central Area) 


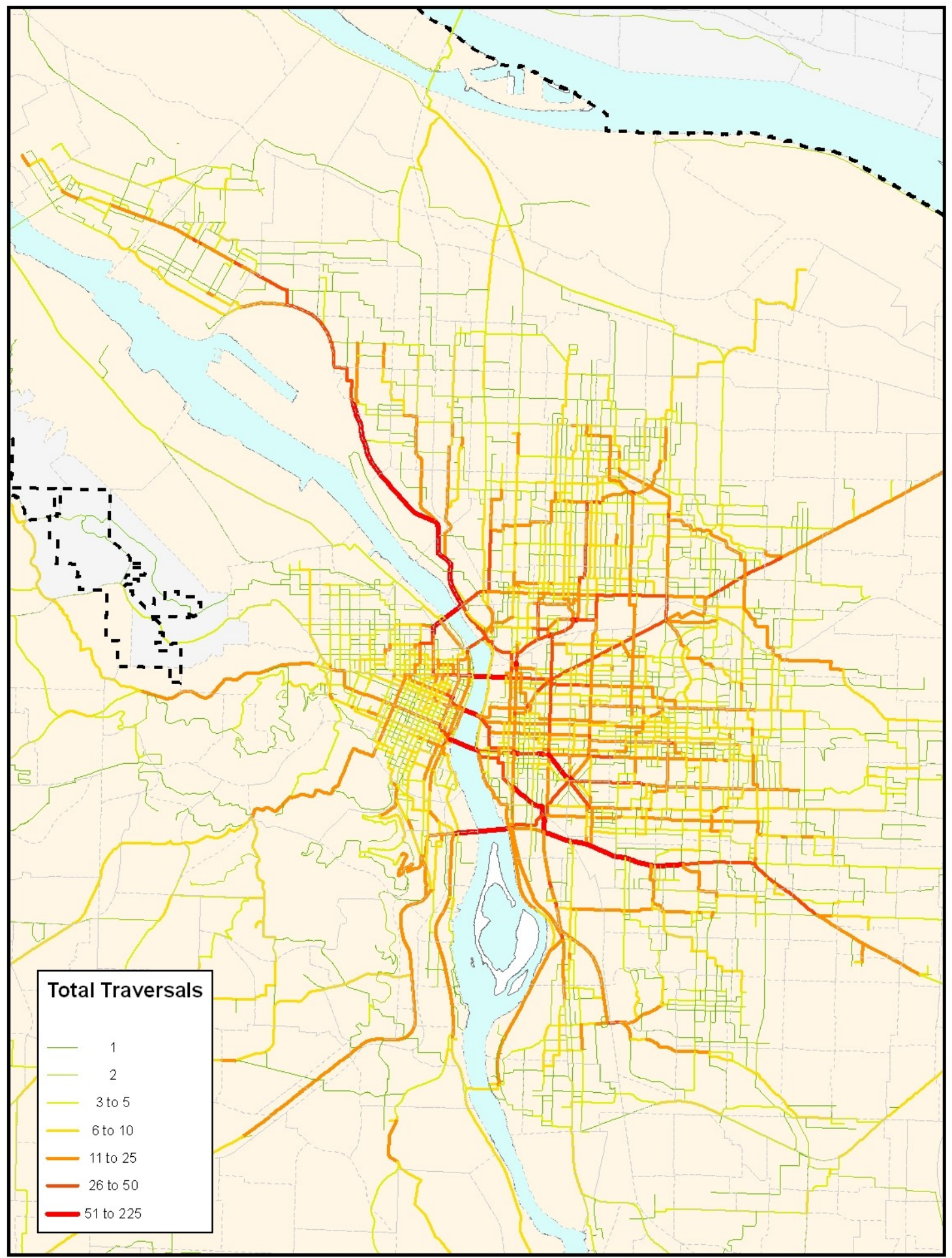

Figure 2.10 Shortest-path Routes for Bicycle Trips (Central Area) 


\subsection{AUTO TRAVEL TIMES}

The same RLIS street network that was used to create the bicycle network was used to create a comparable network from which to derive auto travel times. The idea was to derive realistic auto travel times by time of day and using appropriate roadway facilities. To do this, in addition to all of the regular streets, the freeway facilities that were not available to the bicycle users were included and paths or other off-road facilities were excluded. For congested travel times, GIS was used to overlay the RLIS network on top of a GIS shapefile version of the Metro regional planning network for Portland. The attribute values were then imported for link distances and congested travel speeds in the RLIS network.

The versions of the network available from Metro were taken from the agency's 2005 baseline network for travel demand modeling. Attributes for facility type, distances, free-flow speeds/travel times and congested speeds/travel times were available and used to populate the corresponding attributes on the RLIS network. Free-flow travel times and speeds were the values typically used by Metro in its modeling work, and the congested speeds were the results of network assignment runs for both peak (7-9 a.m. and 4-6 p.m.) and off-peak periods (all other times) of the day. Two versions of the enhanced RLIS auto network were created: one peak and one off-peak. Note that Metro typically only runs a PM Peak highway network; however, congestion effects tend to be symmetrical for most non-freeway facilities.

It should also be noted that the Metro modeled network includes major and minor arterial streets, collectors, ramps and freeway facilities, but does not include most of the local streets that make up residential neighborhoods. Travel times for local streets and similar facilities were added based on the free-flow travel times for facilities of the same functional class that were included in the Metro network. Free-flow travel times are generally coded at or near the posted speed limits, but may be slightly higher for some freeway facilities.

A shortest auto travel time path was generated for each trip for each respondent in the bicyclist survey. To do this, the research team identified the nearest existing network link to the set of XY coordinates representing the origin and the destination of each bicycle trip. ArcGIS Network Analyst's shortest-path algorithm was used to find the least-travel time path through the RLIS auto network, using either the peak or off-peak versions of the network as determined by the starting time of the observed bicycle trip.

The resulting trip travel times represent a linear combination of congested traversal times on arterials, collectors, freeways, ramps and some local streets, with free-flow times used on most residential streets. The Metro model's congested travel times include the effect of traffic signal delays at intersections. The network travel times do not account for time spent parking or accessing an automobile on foot, which would certainly add to the total travel time and could be a significant component of many shorter trips in urbanized areas. Typically, travel demand modelers will add 1 to 2 minutes of "terminal time" for rural and suburban trips, and 5 minutes of terminal time for trips ending in urban areas. 


\subsection{FINDINGS}

\subsection{STUDY PARTICIPANTS}

A majority of the participants were frequent, regular cyclists. When asked to describe themselves as a bicyclist, $83 \%$ of agreed with the statement "I ride a bicycle regularly." This compares with only $12 \%$ of the respondents in the random phone survey (Table 3.1). Three-quarters of the GPS participants stated that they rode their bike 11 or more days a month during the summer. This is about the same as the regular bicyclists from the phone survey, but much more than all bicyclists from the phone survey (Table 3.2). Similarly, most of the GPS participants bicycled regularly during the non-summer months, more so than all bicyclists from the phone survey (Table 3.3).

Table 3.1 Comparison of GPS Participants and Phone Survey Respondents, Type of Bicyclist

\begin{tabular}{lc|c}
\hline $\begin{array}{l}\text { How Would You Describe } \\
\text { Yourself as a Bicyclist? }\end{array}$ & $\begin{array}{l}\text { Phone Survey } \\
\text { Respondents* }\end{array}$ & GPS Participants \\
\hline I never ride a bicycle & $37 \%$ & $0 \%$ \\
\hline I ride a bicycle occasionally & $51 \%$ & $17 \%$ \\
\hline I ride a bicycle regularly & $12 \%$ & $83 \%$ \\
\hline $\mathrm{n}$ & 563 & 162 \\
\hline
\end{tabular}

*Phone survey respondents are weighted based upon sex, age, and education to more closely match the general population.

Table 3.2 Comparison of GPS Participants and Phone Survey Respondents, Frequency of Bicycling in Summer

\begin{tabular}{lc|c|c}
\hline $\begin{array}{l}\text { Number of Days Bicycled per } \\
\text { Month this Past Summer }\end{array}$ & $\begin{array}{c}\text { Phone Survey: } \\
\text { All Bicyclists* }\end{array}$ & $\begin{array}{c}\text { Phone Survey: } \\
\text { Regular } \\
\text { Bicyclists** }\end{array}$ & $\begin{array}{c}\text { GPS } \\
\text { Participants }\end{array}$ \\
\hline Four or fewer & $62 \%$ & $10 \%$ & $8 \%$ \\
\hline 5 to 10 & $17 \%$ & $16 \%$ & $17 \%$ \\
\hline 11 or more & $21 \%$ & $74 \%$ & $75 \%$ \\
\hline $\mathrm{n}$ & 355 & 69 & 162 \\
\hline$*$ Includes respondents who stated that "I ride a bicycle occasionally” and "I ride a bicycle regularly. \\
$* *$ Includes respondents who stated that "I ride a bicycle regularly."
\end{tabular}

Table 3.3 Comparison of GPS Participants and Phone Survey Respondents, Frequency of Bicycling in nonSummer Months

\begin{tabular}{lc|c|c}
\hline $\begin{array}{l}\text { Number of Days Bicycled per } \\
\text { Month in Non-Summer Months }\end{array}$ & $\begin{array}{c}\text { Phone Survey: } \\
\text { All Bicyclists }\end{array}$ & $\begin{array}{c}\text { Phone Survey: } \\
\text { Regular } \\
\text { Bicyclists }\end{array}$ & $\begin{array}{c}\text { GPS } \\
\text { Participants }\end{array}$ \\
\hline Four or fewer & $73 \%$ & $26 \%$ & $27 \%$ \\
\hline 5 to 10 & $8 \%$ & $20 \%$ & $15 \%$ \\
\hline 11 or more & $19 \%$ & $53 \%$ & $57 \%$ \\
\hline $\mathrm{n}$ & 355 & 69 & 162 \\
\hline
\end{tabular}


The GPS participants were slightly older than the regular bicyclists from the phone survey (Table 3.4 ) and had higher incomes (Table 3.5). Nearly three-quarters (73\%) of the GPS participants worked full time, compared to $60 \%$ of the regular bicyclists from the phone survey. The GPS participants were more likely to have a college degree, $80 \%$ compared to $30 \%$ of the regular bicyclists from the phone survey. Similar shares lived in single-person households (13\% of GPS participants and $16 \%$ of regular bicyclists), though a larger share lived in two-person households (48\% and $22 \%$, respectively). Consistent with this, only $39 \%$ of the GPS participants had children under 18 in the household, compared with $49 \%$ of the regular bicyclists from the phone survey. Similar shares of GPS participants were white $(87 \%$ of those who answered the question vs. $93 \%$ of the regular bicyclists).

Table 3.4 Comparison of GPS Participants and Phone Survey Respondents, Age

\begin{tabular}{lc|c|c|c}
\hline Age & $\begin{array}{c}\text { Phone Survey: } \\
\text { Non-Bicyclists }\end{array}$ & $\begin{array}{c}\text { Phone Survey: } \\
\text { All Bicyclists }\end{array}$ & $\begin{array}{c}\text { Phone Survey: } \\
\text { Regular Bicyclists }\end{array}$ & $\begin{array}{c}\text { GPS } \\
\text { Participants }\end{array}$ \\
\hline $18-24$ & $5 \%$ & $13 \%$ & $17 \%$ & $5 \%$ \\
\hline $25-34$ & $9 \%$ & $24 \%$ & $22 \%$ & $27 \%$ \\
\hline $35-44$ & $11 \%$ & $27 \%$ & $37 \%$ & $33 \%$ \\
\hline $45-64$ & $42 \%$ & $29 \%$ & $22 \%$ & $30 \%$ \\
\hline $65+$ & $32 \%$ & $7 \%$ & $2 \%$ & $2 \%$ \\
\hline missing & $1 \%$ & $0 \%$ & $0 \%$ & $4 \%$ \\
\hline $\mathrm{n}$ & 221 & 355 & 69 & 162 \\
\hline
\end{tabular}

Table 3.5 Comparison of GPS Participants and Phone Survey Respondents, Income

\begin{tabular}{lc|c|c|c}
\hline Age & $\begin{array}{c}\text { Phone Survey: } \\
\text { Non-Bicyclists }\end{array}$ & $\begin{array}{c}\text { Phone Survey: } \\
\text { All Bicyclists }\end{array}$ & $\begin{array}{c}\text { Phone Survey: } \\
\text { Regular } \\
\text { Bicyclists }\end{array}$ & $\begin{array}{c}\text { GPS } \\
\text { Participants }\end{array}$ \\
\hline Less than $\$ 25,000$ & $17 \%$ & $14 \%$ & $9 \%$ & $8 \%$ \\
\hline$\$ 25,000$ to less than $\$ 35,000$ & $13 \%$ & $9 \%$ & $15 \%$ & $9 \%$ \\
\hline$\$ 35,000$ to less than $\$ 50,000$ & $12 \%$ & $18 \%$ & $10 \%$ & $8 \%$ \\
\hline$\$ 50,000$ to less than $\$ 75,000$ & $22 \%$ & $20 \%$ & $24 \%$ & $24 \%$ \\
\hline$\$ 75,000$ to less than $\$ 100,000$ & $11 \%$ & $13 \%$ & $11 \%$ & $23 \%$ \\
\hline$\$ 100,000$ to less than $\$ 150,000$ & $7 \%$ & $10 \%$ & $11 \%$ & $16 \%$ \\
\hline$\$ 150,000$ or more & $3 \%$ & $5 \%$ & $7 \%$ & $6 \%$ \\
\hline Don't know/Refused & $15 \%$ & $11 \%$ & $8 \%$ & $5 \%$ \\
\hline $\mathrm{n}$ & 221 & 355 & 69 & 162 \\
\hline
\end{tabular}

Just over half (56\%) of the GPS participants were men, compared to $53 \%$ of all bicyclists and $20 \%$ of the regular bicyclists in the phone survey (Table 3.6). This difference was intentional. If only $20 \%$ of the GPS participants had been women, it would have been difficult to have data from enough women to evaluate their behavior separately. Only $2.5 \%$ of the GPS participants did not have a driver's license and only $7 \%$ did not have any motor vehicles as home. Therefore, most participants did have the option to drive for some or all of their travel. 
Table 3.6 Comparison of GPS Participants and Phone Survey Respondents, Sex

\begin{tabular}{lc|c|c|c}
\hline Age & $\begin{array}{c}\text { Phone Survey: } \\
\text { Non-Bicyclists }\end{array}$ & $\begin{array}{c}\text { Phone Survey: } \\
\text { All Bicyclists }\end{array}$ & $\begin{array}{c}\text { Phone Survey: } \\
\text { Regular } \\
\text { Bicyclists }\end{array}$ & $\begin{array}{c}\text { GPS } \\
\text { Participants }\end{array}$ \\
\hline Male & $37 \%$ & $53 \%$ & $80 \%$ & $56 \%$ \\
\hline Female & $63 \%$ & $47 \%$ & $20 \%$ & $44 \%$ \\
\hline $\mathrm{n}$ & 221 & 355 & 69 & 162 \\
\hline
\end{tabular}

\subsection{BICYCLING BEHAVIOR OF PARTICIPANTS}

\subsubsection{Overall Trips and Mileage}

Participants made an average of 1.6 bicycle one-way trips ${ }^{4}$ per day that they had the GPS device. The median number of trips per day was 1.4. Most participants made two or few trips per day while they had the GPS device; 38\% made one or fewer trips per day and an equal share made more than one and up to two trips per day (Table 3.7). Participants rode an average of 6.2 miles per day (standard deviation 5.2), with a median of 4.9 miles. Just over half (51\%) of the participants biked less than five miles per day and 85\% bicycled less than 10 miles per day. This includes all of the days the participant had the GPS device, which may include days not bicycling at all. The distribution of participants by miles bicycled per day is shown in Figure 3.1.

Table 3.7 Number of Bicycle Trips per Day Recorded

\begin{tabular}{l|c|c}
\hline Trips per Day Recorded & Number & Percent \\
\hline One or fewer & 62 & $38 \%$ \\
\hline$>1$ to 2 & 62 & $38 \%$ \\
\hline$>2$ to 3 & 23 & $14 \%$ \\
\hline$>3$ to 4 & 8 & $5 \%$ \\
\hline$>4$ to 5 & 6 & $4 \%$ \\
\hline More than 5 & 1 & $1 \%$ \\
\hline Total & 162 & $100 \%$ \\
\hline
\end{tabular}

\footnotetext{
${ }^{4}$ A trip is generally defined as each time the person rode from one destination to another. This was indicated by the participant turning the unit on or off, changing the destination, or inactivity for more than five minutes. "Loop" trips that started and ended at the same location with no other destination (common for exercise trips) are the same as a one-way trip.
} 


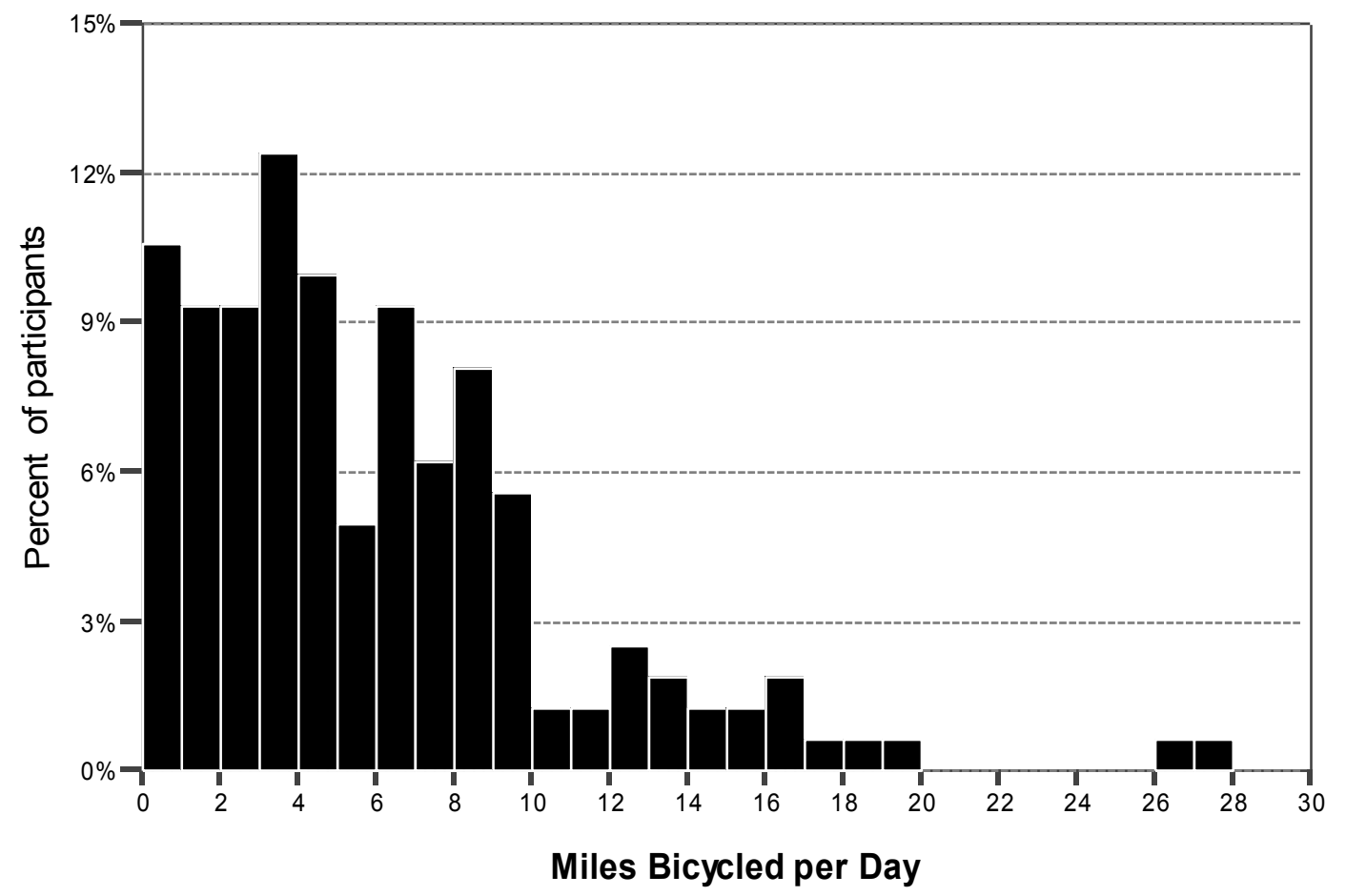

Figure 3.1 Miles Bicycled per Day

The average number of trips per day declines with age (Figure 3.2). There is no clear pattern for miles per day. While the participants 65 or older biked far fewer miles, there were only three such participants, so caution must be used when drawing conclusions from that group. Women rode significantly fewer miles per day (mean 5.0 vs. 7.2 for men), but about the same number of trips (1.6 vs. 1.5 , respectively). 


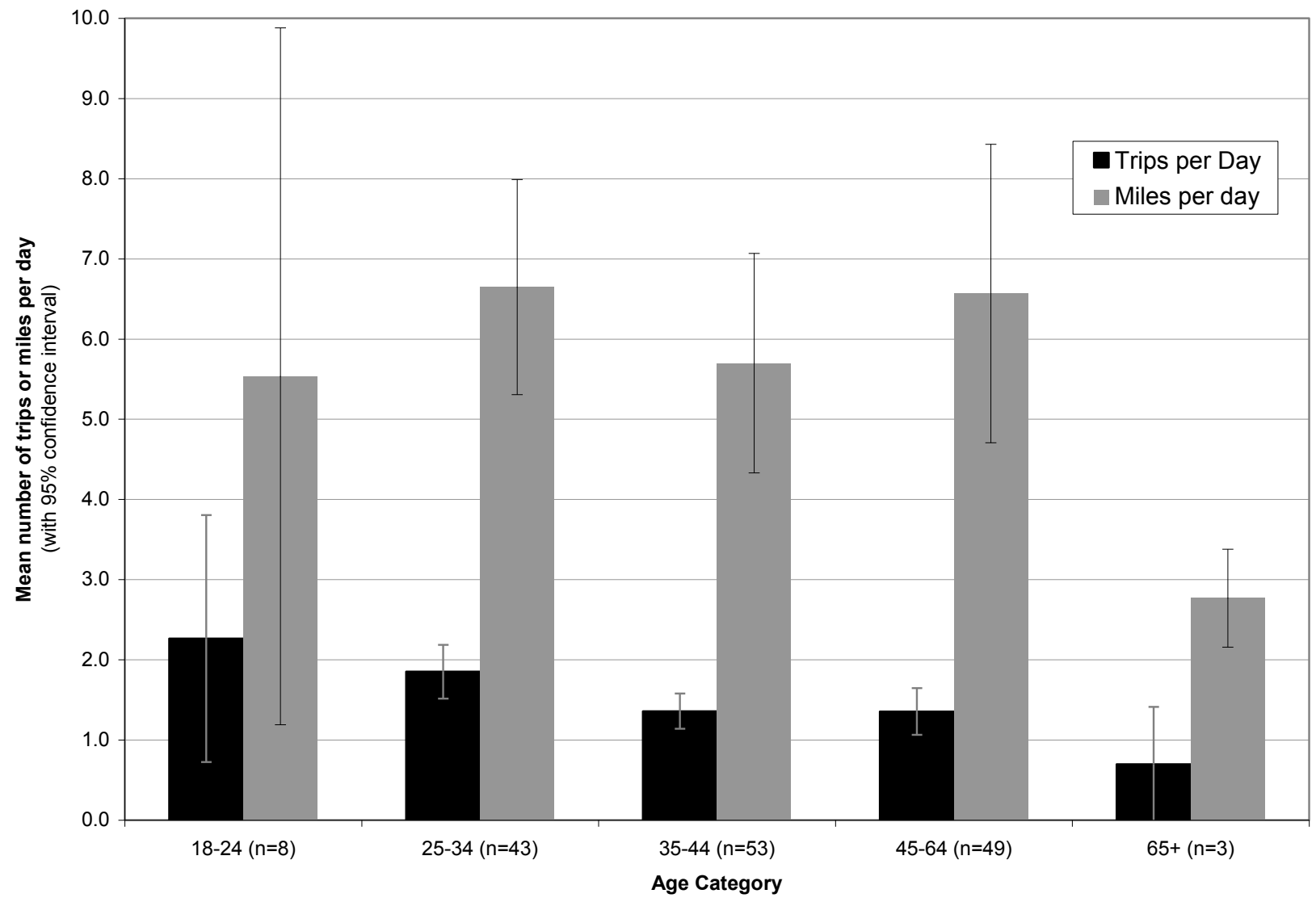

Figure 3.2 Mean Number of Trips and Miles per Day, by Age

\subsubsection{Trip Purposes}

Aside from home, the most frequent trip destination was work (Table 3.8); $25 \%$ of the trips were for this purpose. The fact that one-third (rather than half) of the trips were returning home indicates that some trip-chaining is occurring. Only 5\% of the trips were purely for exercise. About $18 \%$ of the trips were for shopping, dining out, and personal business. 
Table 3.8 Bicycle Trip Purposes

\begin{tabular}{l|c|c|c|c}
\hline \multirow{2}{*}{ Trip Destination } & \multicolumn{2}{|c|}{ All Recorded Trips* } & \multicolumn{2}{c}{ Bicycle-Only Trips } \\
\cline { 2 - 5 } work & Number & Percent & Number & Percent \\
\hline work-related & 489 & $25.1 \%$ & 445 & $25.0 \%$ \\
\hline school & 61 & $3.1 \%$ & 58 & $3.3 \%$ \\
\hline shopping & 23 & $1.2 \%$ & 20 & $1.1 \%$ \\
\hline dining & 127 & $6.5 \%$ & 117 & $6.6 \%$ \\
\hline personal business & 57 & $2.9 \%$ & 54 & $3.0 \%$ \\
\hline social/recreation & 155 & $7.9 \%$ & 142 & $8.0 \%$ \\
\hline home & 243 & $12.4 \%$ & 218 & $12.3 \%$ \\
\hline exercise & 644 & $33.0 \%$ & 586 & $33.0 \%$ \\
\hline other & 99 & $5.1 \%$ & 94 & $5.3 \%$ \\
\hline \multicolumn{1}{c|}{ organized ride } & 31 & $1.6 \%$ & 21 & $1.2 \%$ \\
\hline extended trip for exercise & 19 & $1.0 \%$ & 18 & $1.0 \%$ \\
\hline Total & 4 & $0.2 \%$ & 4 & $0.2 \%$ \\
\hline
\end{tabular}

* includes trips with a portion on transit or walking with bike

\subsubsection{Trip Distances}

The average bicycle trip (only trips made entirely by bicycle) was 4.3 miles long and the median was 2.8 miles. Seventy-five percent of the bicycle trips were 5.3 miles or shorter. Nearly $40 \%$ of the trips were two miles or less (Table 3.9). Exercise trips were significantly longer than other trips, with a median length of 8.5 miles (Table 3.10). The median trip distance to work was 3.8 miles, at least one mile longer than other trip destinations.

Table 3.9 Bicycle Trip Distances

\begin{tabular}{l|c|c}
\hline \multirow{2}{*}{ Miles Bicycled On Trip } & \multicolumn{2}{|c}{ Bicycle-Only Trips } \\
\cline { 2 - 3 } 1 mile or less & Number & Percent \\
\hline$>1$ to 2 miles & 383 & $21.6 \%$ \\
\hline$>2$ to 3 miles & 323 & $18.2 \%$ \\
\hline$>3$ to 4 miles & 234 & $13.2 \%$ \\
\hline$>4$ to 5 miles & 206 & $11.6 \%$ \\
\hline$>5$ to 6 miles & 139 & $7.8 \%$ \\
\hline$>6$ to 7 miles & 113 & $6.4 \%$ \\
\hline$>7$ to 8 miles & 82 & $4.6 \%$ \\
\hline$>8$ to 9 miles & 67 & $3.8 \%$ \\
\hline$>9$ to 10 miles & 42 & $2.4 \%$ \\
\hline More than 10 miles & 39 & $2.2 \%$ \\
\hline Total & 149 & $8.4 \%$ \\
\hline
\end{tabular}


Table 3.10 Bicycle Trip Distance by Purpose

\begin{tabular}{l|c|c|c|c}
\hline Trip Purpose & Median & Mean & $\begin{array}{c}\text { Std. } \\
\text { Deviation }\end{array}$ & N \\
\hline Exercise & 8.5 & 12.7 & 13.2 & 94 \\
\hline Work & 3.8 & 5.2 & 5.2 & 445 \\
\hline Home & 2.8 & 3.7 & 3.5 & 586 \\
\hline Social/recreation & 2.1 & 3.6 & 4.9 & 218 \\
\hline School & 1.8 & 2.8 & 3.1 & 20 \\
\hline Work-related & 1.7 & 2.6 & 2.8 & 58 \\
\hline Shopping & 1.3 & 2.4 & 4.4 & 117 \\
\hline Personal business & 1.3 & 2.4 & 2.6 & 142 \\
\hline Dining & 1.0 & 2.0 & 2.3 & 54 \\
\hline All trips & 2.8 & 4.3 & 5.6 & 1,777 \\
\hline
\end{tabular}

\subsubsection{Trip Speeds}

The average overall speed for the bicycle-only trips was 10.8 miles per hour (standard deviation 3.2), including times when the bicycle was not moving. Removing times when the GPS recorded zero velocity (e.g., when the bicyclist was stopped at a light), the average speed was 11.1 miles per hour (standard deviation 3.2). The median speeds were also 10.8 and $11.1 \mathrm{mph}$, respectively. Half of all trips were between $8.9 \mathrm{mph}\left(25^{\text {th }}\right.$ percentile) and $12.9 \mathrm{mph}\left(75^{\text {th }}\right.$ percentile $)$ (including zero velocity). Trips to work, school, and work-related destinations had the highest average speeds $-12.0 \mathrm{mph}$. Women's trips were slower, averaging $9.8 \mathrm{mph}$ compared to $11.6 \mathrm{mph}$ for men.

Table 3.11 Bicycle Trip Speeds by Purpose

\begin{tabular}{l|c|c|c|c}
\hline Trip Purpose & Median & Mean & $\begin{array}{c}\text { Std. } \\
\text { Deviation }\end{array}$ & N \\
\hline Work, work-related, school & 12.0 & 12.0 & 2.9 & 523 \\
\hline Exercise \& organized rides & 11.7 & 11.3 & 3.9 & 116 \\
\hline Home & 10.5 & 10.5 & 3.0 & 586 \\
\hline Social/recreation & 10.3 & 10.1 & 3.2 & 218 \\
\hline $\begin{array}{l}\text { Shopping, dining, personal } \\
\text { business, other }\end{array}$ & 9.6 & 9.6 & 3.2 & 333 \\
\hline All trips & 10.8 & 10.8 & 3.2 & 1,776 \\
\hline
\end{tabular}

Speed is average speed recorded by GPS, including zero velocity recordings.

\subsubsection{Time of Day and Weather}

The distribution of trip starting times is shown in Figure 3.3. Half of the trips started during what could be considered the morning and afternoon peak travel periods (6-9 a.m. and 4-7 p.m.), with $34.1 \%$ starting in the midday, between those two periods (Table 3.12 ). Nearly $12 \%$ of the trips started in the evening between 7 p.m. and midnight. The distribution varies by trip purpose (Table 3.13). As would be expected, a higher share of trips to work started between 6a.m. and 8:59 a.m., compared to other trip purposes. Trips for shopping, dining and personal business 
were more likely to happen midday. Trips for social/recreation and back home were the most likely trip purpose to happen at night.

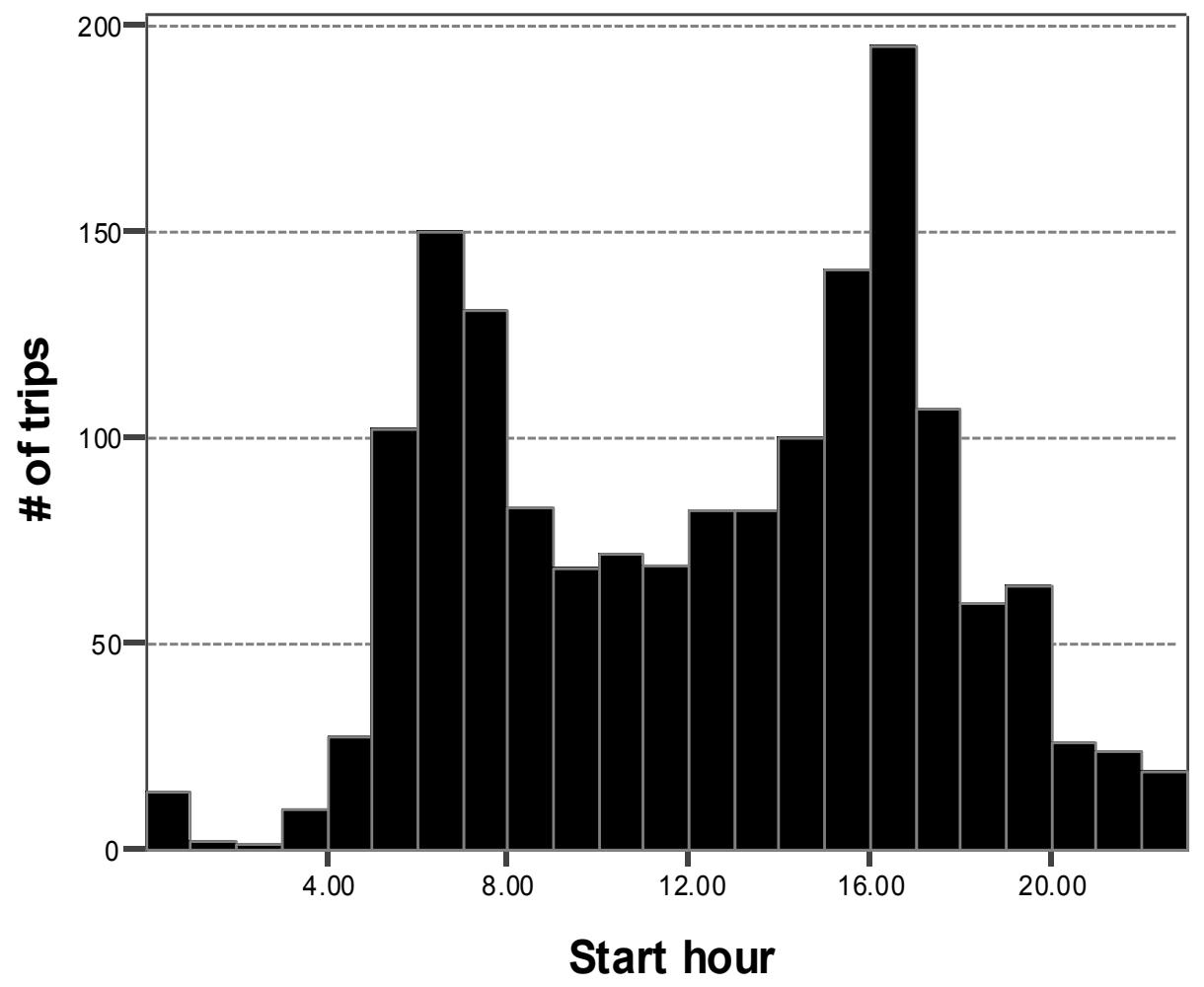

Figure 3.3 Distribution of Bicycle Trip Start Times, by Hour

Table 3.12 Bicycle Trip Start Times

\begin{tabular}{l|c|c}
\hline Trip Start Time & $\begin{array}{c}\text { \% of } \\
\text { Trips }\end{array}$ & N \\
\hline 12:01 - 5:59 a.m. & $3.0 \%$ & 54 \\
\hline 6:00-8:59 a.m. & 23.5 & 383 \\
\hline 9:00 a.m. - 3:59 p.m. & 34.1 & 556 \\
\hline 4:00 - 6:59 p.m. & 27.2 & 443 \\
\hline 7:00 p.m. - midnight & 11.8 & 193 \\
\hline & 100.0 & 1,629 \\
\hline
\end{tabular}

Note: Bicycle-only trips 
Table 3.13 Bicycle Trip Start Times, by Trip Purpose

\begin{tabular}{l|c|c|c|c|c}
\hline Trip Start Time & $\begin{array}{c}\text { Work, Work- } \\
\text { Related, } \\
\text { School }\end{array}$ & $\begin{array}{c}\text { Shopping, } \\
\text { Dining, } \\
\text { Personal } \\
\text { Business, } \\
\text { Other }\end{array}$ & $\begin{array}{c}\text { Social/ } \\
\text { Recreational }\end{array}$ & Home & $\begin{array}{c}\text { Exercise and } \\
\text { Organized } \\
\text { Rides }\end{array}$ \\
\hline 12:01 - 5:59 a.m. & $5.2 \%$ & $1.0 \%$ & $3.4 \%$ & $2.8 \%$ & $2.9 \%$ \\
\hline 6:00 - 8:59 a.m. & 60.4 & 15.4 & 6.4 & 1.5 & 16.3 \\
\hline 9:00 a.m. $-3: 59$ p.m. & 27.6 & 50.7 & 39.7 & 23.7 & 61.5 \\
\hline 4:00-6:59 p.m. & 6.2 & 26.7 & 30.4 & 47.9 & 16.3 \\
\hline 7:00 p.m. - midnight & 0.6 & 6.2 & 20.1 & 24.1 & 2.9 \\
\hline $\mathrm{n}$ & 497 & 292 & 204 & 532 & 104
\end{tabular}

The majority of the bicycle-only trips occurred under moderate weather conditions, as reported by the participants (Table 3.14). About half of the trips occurred when it was "sunny/clear" while $27.7 \%$ occurred when it was cloudy, but not raining. Just under $9 \%$ of the trips started in the rain, while $13.6 \%$ started when it was cloudy and might rain.

Table 3.14 Self-reported Weather Conditions

\begin{tabular}{l|c|c}
\hline & $\begin{array}{c}\text { \%of } \\
\text { Trips }\end{array}$ & $\mathbf{N}$ \\
\hline Overall Weather & & \\
\hline Sunny/clear & $49.5 \%$ & 879 \\
\hline Cloudy, no rain & 27.7 & 493 \\
\hline Cloudy, may rain & 13.6 & 242 \\
\hline Fog & 0.1 & 1 \\
\hline Light rain & 7.6 & 135 \\
\hline Heavy rain & 1.1 & 20 \\
\hline Wind & & \\
\hline No wind & 51.1 & 908 \\
\hline Light wind & 47.3 & 841 \\
\hline Heavy wind & 1.2 & 21 \\
\hline Temperature & & \\
\hline Moderate & 78.6 & 1,396 \\
\hline Hot & 9.1 & 161 \\
\hline Cold & 12.0 & 213 \\
\hline & & 1,770 \\
\hline Note: Bicycleny
\end{tabular}

Note: Bicycle-only trips

\subsubsection{Route Choice Priorities}

Participants were asked about the importance of seven different factors in choosing each trip route. Rather than being comprehensive, the list of factors focused on infrastructure - things that can be changed by public policy or investment. Minimizing total travel distance and avoiding 
streets with lots of vehicle traffic were consistently the highest ranked factors (Table 3.15). The only exception was for exercise and organized ride trips, where minimizing distance was a low priority.

There were some other differences in priorities between different trip destinations. Minimizing distance was most important for trips to work, work-related destinations, and school. This makes sense, since those trips often involve the need to arrive at a certain time. Also, they were generally longer trips. Avoiding streets with lots of vehicle traffic was most important for trips returning home. The reason for this is less clear. It may be that people want less stress on the ride home rather than the focus on getting there in the most direct manner. Riding in a bike lane was ranked third for most trip purposes, while riding on a path or trail was ranked low, except for exercise trips. The low ranking for the utilitarian trips is likely influenced by geography; if there is no path within a reasonable distance, a person is likely to rule out riding on one as a factor in their route choice. Similarly, avoiding hills was not a high priority, though this may vary spatially.

Because of the difference in priorities for exercise trips, and because people usually do not influence the route choice for organized rides, these trips are excluded from much of the analysis that follows. In addition, trips that started and ended at about the same place - defined as within 200 feet - are also excluded from some of the analysis. Trips that are 200 feet or less likely fall into one of three categories. First, they may be "real" trips that are just very short. In which case, there are not many decisions to make about the route. Second, they may be loop trips, in which case they are or are similar to exercise trips where riding is the primary purpose. In this case, route choice decisions may be very different from other trips. Finally, there may be errors in the data. There were 86 such trips, of which 28 were for exercise or organized rides and 24 had a destination of home. Many of the "home" trips may also have been exercise loop trips that started and ended at home. Eleven of the trips were marked as social/recreation. 
Table 3.15 Factors Influencing Trip Route Choice, by Trip Destination

\begin{tabular}{|c|c|c|c|c|c|}
\hline & \multicolumn{5}{|c|}{$\begin{array}{c}\text { Mean Score, 1-5 Scale, 1=Not At All Important, 5=Very Important } \\
\text { (Ranking In Parentheses) }\end{array}$} \\
\hline & $\begin{array}{c}\text { Work, } \\
\text { Work- } \\
\text { Related, } \\
\text { School }\end{array}$ & $\begin{array}{c}\text { Shopping, } \\
\text { Dining, } \\
\text { Personal } \\
\text { Business, } \\
\text { Other }\end{array}$ & $\begin{array}{c}\text { Social/ } \\
\text { Recreational }\end{array}$ & $\begin{array}{c}\text { Exercise \& } \\
\text { Organized } \\
\text { Rides }\end{array}$ & Home \\
\hline Minimize distance & $3.84(1)$ & $3.59(1)$ & $3.21(2)$ & $1.60(6)$ & $3.62(2)$ \\
\hline Ride in bike lane & $3.23(3)$ & $2.60(3)$ & $2.79(3)$ & $2.68(2)$ & $3.00(3)$ \\
\hline Ride on path/trail & $2.36(6)$ & $1.91(7)$ & $2.14(7)$ & $2.47(3)$ & $2.29(6)$ \\
\hline $\begin{array}{l}\text { Ride on signed bike } \\
\text { route }\end{array}$ & $2.80(5)$ & $2.31(5)$ & $2.60(4)$ & $2.27(4)$ & $2.68(4)$ \\
\hline $\begin{array}{l}\text { Avoid streets with lots } \\
\text { of traffic }\end{array}$ & $3.59(2)$ & $3.39(2)$ & $3.44(1)$ & $3.56(1)$ & $3.72(1)$ \\
\hline Avoid hills & $2.07(7)$ & $2.04(6)$ & $2.16(6)$ & $1.71(7)$ & $2.12(7)$ \\
\hline $\begin{array}{l}\text { Reduce wait time at } \\
\text { signs/lights }\end{array}$ & $2.87(4)$ & $2.44(4)$ & $2.52(5)$ & $2.25(5)$ & $2.68(5)$ \\
\hline $\mathrm{n}$ & 528 to 520 & 357 to 358 & 229 to 230 & 108 to 113 & 596 to 603 \\
\hline
\end{tabular}

Notes: $\mathrm{n}$ varies due to non-response on individual questions.

Riding with another adult or with a child appears to influence route choice. If another adult was on the trip, minimizing distance rose in importance, while avoiding high-traffic streets and riding in a bike lane fell in importance. If a child was on the trip, avoiding streets with lots of traffic became significantly more important, averaging over 4 on a 1-5 scale. Minimizing distance was also important. Riding on a path or trail was also significantly more important if a child was on the trip than if not, as was avoiding hills. While these findings make logical sense, it should be noted that there were only 87 trips with a child, made by 11 participants. This also only includes non-exercise trips, though there were only seven exercise trips with children. 
Table 3.16 Factors Influencing Trip Route Choice, Trips With and Without Adults or Children

\begin{tabular}{l|c|c|c|c|c|c|c|c}
\hline \multirow{2}{*}{} & \multicolumn{3}{|c|}{ Another Adult was on Trip } & \multicolumn{3}{c}{ A Child was on Trip } \\
\cline { 2 - 10 } & \multicolumn{2}{|c|}{ No } & \multicolumn{2}{c}{ Yes } & \multicolumn{2}{c}{ No } & \multicolumn{2}{c}{ Yes } \\
\cline { 2 - 10 } & Mean & Rank & Mean & Rank & Mean & Rank & Mean & Rank \\
\hline Minimize distance & $\mathbf{3 . 5 4}$ & 2 & $\mathbf{3 . 8 8}$ & 1 & 3.65 & 1 & 3.87 & 2 \\
\hline Ride in bike lane & $\mathbf{3 . 0 8}$ & 3 & $\mathbf{2 . 8 4}$ & 3 & 3.00 & 3 & 2.98 & 3 \\
\hline Ride on path/trail & $\mathbf{2 . 3 1}$ & 6 & $\mathbf{2 . 0 9}$ & 7 & $\mathbf{2 . 2 2}$ & 6 & $\mathbf{2 . 5 7}$ & 7 \\
\hline $\begin{array}{l}\text { Ride on signed bike } \\
\text { route }\end{array}$ & $\mathbf{2 . 7 2}$ & 4 & $\mathbf{2 . 5 6}$ & 5 & 2.66 & 5 & 2.72 & $4-$-tie \\
\hline $\begin{array}{l}\text { Avoid streets with lots } \\
\text { of traffic }\end{array}$ & $\mathbf{3 . 7 4}$ & 1 & $\mathbf{3 . 3 6}$ & 2 & $\mathbf{3 . 5 8}$ & 2 & $\mathbf{4 . 0 8}$ & 1 \\
\hline $\begin{array}{l}\text { Avoid hills } \\
\text { Reduce wait time at } \\
\text { signs/lights }\end{array}$ & $\mathbf{1 . 9 8}$ & 7 & $\mathbf{2 . 3 6}$ & 6 & $\mathbf{2 . 0 8}$ & 7 & $\mathbf{2 . 6 2}$ & 6 \\
\hline $\mathrm{n}$ & \multicolumn{2}{|c|}{973 to 986} & $\mathbf{2 . 8 2}$ & 4 & 2.69 & 4 & 2.72 & $4-$-tie \\
\hline
\end{tabular}

Notes: $\mathrm{n}$ varies due to non-response on individual questions.

Bold indicates a significant difference between the two groups, $\mathrm{p}<0.05$.

Excludes trips for exercise, organized rides, and trips starting and ending at the same location.

On average, men and women ranked the route choice factors in the same order (Table 3.17). Women rated three factors significantly higher in importance than men - minimizing distance, avoiding streets with lots of traffic, and avoiding hills. With one exception - riding in a bike lane - women rated all of the factors more important than men, though the difference was only significant for those three.

Table 3.17 Factors Influencing Trip Route Choice, by Sex

\begin{tabular}{l|l|l|l|l}
\hline \multirow{2}{*}{} & \multicolumn{4}{|c}{ Mex } \\
\cline { 2 - 5 } & Mean & Rank & Mean & Rank \\
\hline Minimize distance & $\mathbf{3 . 4 9}$ & $\mathbf{1}$ & $\mathbf{3 . 8 5}$ & $\mathbf{1}$ \\
\hline Ride in bike lane & 3.03 & 3 & 2.99 & 3 \\
\hline Ride on path/trail & 2.18 & 6 & 2.31 & 6 \\
\hline $\begin{array}{l}\text { Ride on signed bike } \\
\text { route }\end{array}$ & 2.63 & 4 -tie & 2.71 & 4-tie \\
\hline $\begin{array}{l}\text { Avoid streets with lots } \\
\text { of traffic }\end{array}$ & $\mathbf{3 . 4 8}$ & $\mathbf{2}$ & $\mathbf{3 . 7 5}$ & $\mathbf{2}$ \\
\hline Avoid hills & $\mathbf{1 . 9 6}$ & $\mathbf{7}$ & $\mathbf{2 . 3 0}$ & $\mathbf{7}$ \\
\hline $\begin{array}{l}\text { Reduce wait time at } \\
\text { signs/lights }\end{array}$ & 2.63 & $4-$-tie & 2.71 & 4-tie \\
\hline $\mathrm{n}$ & \multicolumn{2}{|c|}{787 to 800} & \multicolumn{2}{c}{691 to 694 } \\
\hline
\end{tabular}

Notes: $\mathrm{n}$ varies due to non-response on individual questions.

Bold indicates a significant difference between the two groups, $\mathrm{p}<0.05$.

Excludes trips for exercise, organized rides, and trips starting and ending at the same location.

It is likely that experienced and inexperienced cyclists have different route priorities. Defining experience is difficult. There was no question on the survey that asked participants to generally describe their experience. There were questions about how often (days per month) they bicycled 
in the summer and non-summer months. Using these questions, the participants were divided into groups with cutoffs of 10 days per month in the summer and 4 days per month in nonsummer months. The differences in route choice preferences between these groups are shown in Table 3.18. Frequent summer bicyclists (more than 10 days per month) rated riding in bike lanes and on signed bike routes and reducing wait time higher than those who cycled less frequently. Those who bicycled more frequently in the non-summer months placed less importance on riding on paths or trails, avoiding streets with lots of traffic, and avoiding hills.

Table 3.18 Factors Influencing Trip Route Choice, by Bicycling Frequency

\begin{tabular}{|c|c|c|c|c|c|c|c|c|}
\hline & \multicolumn{4}{|c|}{$\begin{array}{c}\text { Number of Days Bicycling } \\
\text { Per Month In Summer }\end{array}$} & \multicolumn{4}{|c|}{$\begin{array}{l}\text { Number of Days Bicycling } \\
\text { Per Month In Non-Summer }\end{array}$} \\
\hline & \multicolumn{2}{|c|}{10 or Fewer } & \multicolumn{2}{|c|}{ More Than 10} & \multicolumn{2}{|c|}{4 or Fewer } & \multicolumn{2}{|c|}{ More Than 4} \\
\hline & Mean & Rank & Mean & Rank & Mean & Rank & Mean & Rank \\
\hline Minimize distance & 3.80 & 1 & 3.65 & 1 & 3.77 & 2 & 3.66 & 1 \\
\hline Ride in bike lane & 2.82 & 3 & 3.05 & 3 & 3.01 & 3 & 3.03 & 3 \\
\hline Ride on path/trail & 2.14 & 7 & 2.25 & 6 & 2.73 & 4 & 2.16 & 6 \\
\hline $\begin{array}{l}\text { Ride on signed bike } \\
\text { route }\end{array}$ & 2.25 & 5-tie & 2.75 & 5 & 2.66 & 6 & 2.69 & 5 \\
\hline $\begin{array}{l}\text { Avoid streets with lots } \\
\text { of traffic }\end{array}$ & 3.76 & 2 & 3.59 & 2 & 3.91 & 1 & 3.58 & 2 \\
\hline Avoid hills & 2.25 & 5-tie & 2.12 & 7 & 2.37 & 7 & 2.11 & 7 \\
\hline $\begin{array}{l}\text { Reduce wait time at } \\
\text { signs/lights }\end{array}$ & 2.40 & 4 & 2.76 & 4 & 2.67 & 5 & 2.73 & 4 \\
\hline number of trips & \multicolumn{2}{|c|}{$\begin{array}{c}194 \text { to } 198 \\
\text { (39 participants) }\end{array}$} & \multicolumn{2}{|c|}{$\begin{array}{c}1,250 \text { to } 1,263 \\
\text { (119 participants) }\end{array}$} & \multicolumn{2}{|c|}{$\begin{array}{c}87 \\
(34 \text { participants })\end{array}$} & \multicolumn{2}{|c|}{$\begin{array}{c}1415 \text { to } 1427 \\
\text { (123 participants) }\end{array}$} \\
\hline
\end{tabular}

Notes: $\mathrm{n}$ varies due to non-response on individual questions.

Bold indicates a significant difference between the two groups, $\mathrm{p}<0.05$.

Excludes trips for exercise, organized rides, and trips starting and ending at the same location.

Finally, the survey also asked people whether they agreed or disagreed with a series of statements about various mobility options. One statement was "Traveling by car is safer than bicycle." Fifty-eight percent (72) of the participants agreed either strongly or somewhat with this statement. Those who did rated riding in a bike lane and on a path or trail of higher importance in their trip route choices (Table 3.19). 
Table 3.19 Factors Influencing Trip Route Choice, by Safety Attitude

\begin{tabular}{|c|c|c|c|c|}
\hline & \multicolumn{4}{|c|}{ Traveling By Car Is Safer Than Bicycle } \\
\hline & Disagree & Rank & Agree & Rank \\
\hline Minimize distance & 3.51 & 2 & 3.66 & 2 \\
\hline Ride in bike lane & 2.99 & 3 & 3.21 & 3 \\
\hline Ride on path/trail & 2.22 & 7 & 2.48 & 6 \\
\hline $\begin{array}{l}\text { Ride on signed bike } \\
\text { route }\end{array}$ & 2.75 & 5 & 2.66 & 4 \\
\hline $\begin{array}{l}\text { Avoid streets with lots } \\
\text { of traffic }\end{array}$ & 3.65 & 1 & 3.66 & 1 \\
\hline Avoid hills & 2.38 & 6 & 2.05 & 7 \\
\hline $\begin{array}{l}\text { Reduce wait time at } \\
\text { signs/lights }\end{array}$ & 2.88 & 4 & 2.66 & 5 \\
\hline number of trips & \multicolumn{2}{|c|}{$\begin{array}{c}559 \text { to } 569 \\
\text { (52 participants) }\end{array}$} & \multicolumn{2}{|c|}{$\begin{array}{c}564 \text { to } 567 \\
\text { (72 participants) }\end{array}$} \\
\hline
\end{tabular}

\subsubsection{Routes by Facility Type}

When the bicyclists were riding for utilitarian purposes, they rode mainly on facilities with bicycle infrastructure. Over half $(52 \%)$ of the miles on bicycle-only trips that were not loops, for exercise, or organized rides were made on facilities with bicycle infrastructure, including lanes, separate paths, or bicycle boulevards (Table 3.20). Over one-quarter of the mileage (28\%) occurred on streets (arterials or minor streets) with bike lanes. The GPS data, however, are not precise enough to indicate whether the person was bicycling in the bike lane, in a motor vehicle traffic lane, or on the sidewalk. An equal share (28\%) of the mileage occurred on minor streets without bike lanes. These are typically low traffic volume, residential streets. Therefore, only $19 \%$ of the travel was on streets that would be expected to have high volumes of motor vehicle traffic and no separate facility for a bicycle.

Bicycling for exercise followed a different pattern. Nearly two-thirds (64\%) of this travel was on roads without bike lanes. This reflects, in part, a significant amount of exercise travel in more rural areas. As Figure 2.7 showed on page 16, there were several long trips outside of the urban growth boundary. Overall, smaller shares of the exercise riding occurred on more urban facilities - streets with bike lanes and bicycle boulevards. The exception is the use of regional multi-use paths; $15 \%$ of the exercise travel occurred on these facilities. Many of these paths are in urban areas, such as the Springwater Corridor, Eastbank Esplanade and Tom McCall Waterfront, I-205, and Marine Drive paths. 
Table 3.20 Bicycle Travel by Facility Type

\begin{tabular}{|c|c|c|c|c|}
\hline \multirow[b]{2}{*}{ Facility Type } & \multicolumn{2}{|c|}{$\begin{array}{l}\text { Utilitarian, Non-Loop } \\
\text { Bicycle-Only Trips* }\end{array}$} & \multicolumn{2}{|c|}{$\begin{array}{l}\text { Exercise and Loop } \\
\text { Bicycle-Only Trips }\end{array}$} \\
\hline & Miles & $\%$ of Miles & Miles & $\%$ of Miles \\
\hline \multicolumn{5}{|l|}{ Facilities with no bicycle infrastructure } \\
\hline Primary arterial or highway, no bike lanes & 189 & $3 \%$ & 74 & $6 \%$ \\
\hline Secondary arterial, no bike lanes & 959 & $16 \%$ & 448 & $33 \%$ \\
\hline Minor streets, no bike lanes & 1,746 & $28 \%$ & 301 & $22 \%$ \\
\hline Driveway/alley/unimproved road, no bike lanes & 67 & $1 \%$ & 47 & $3 \%$ \\
\hline Subtotal & & $48 \%$ & & $64 \%$ \\
\hline \multicolumn{5}{|l|}{ Facilities with bicycle infrastructure } \\
\hline Primary arterial or highway, with bike lane & 573 & $9 \%$ & 76 & $6 \%$ \\
\hline Secondary arterial, with bike lane & 935 & $15 \%$ & 143 & $10 \%$ \\
\hline Minor streets, with bike lane & 200 & $3 \%$ & 19 & $1 \%$ \\
\hline Regional multi-use path** & 797 & $13 \%$ & 203 & $15 \%$ \\
\hline Local multi-use path** & 41 & $1 \%$ & 9 & $1 \%$ \\
\hline Bicycle boulevard & 623 & $10 \%$ & 43 & $3 \%$ \\
\hline Subtotal & & $52 \%$ & & $36 \%$ \\
\hline Total & 6,131 & $100 \%$ & 1,362 & $100 \%$ \\
\hline
\end{tabular}

Overall, $70 \%$ of the bicycle-only trips included some travel on a facility with a bike lane, $40 \%$ included some travel on a bicycle boulevard, and 38\% included some travel on a regional multiuse path. For any individual trip, the average share of the trip on a facility with a bike lane was $21 \%$, with a median of $13 \%$. The distribution is shown in Figure 3.4. On average, only $9 \%$ of any trip is spent on a regional or local multi-use path. That distribution is shown in Figure 3.5. 


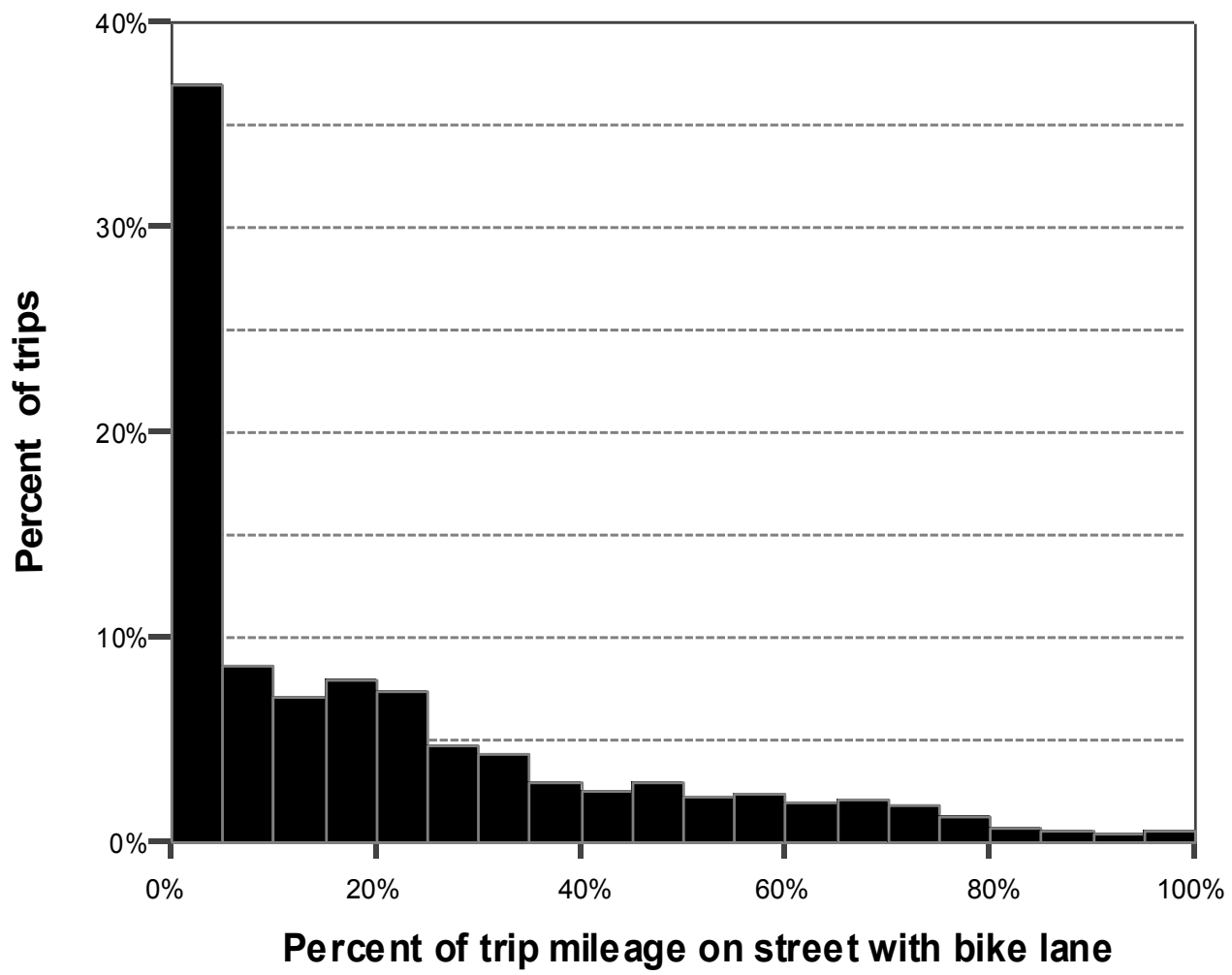

Figure 3.4 Distribution of Trips by Percent of Trip Mileage on Streets with Bike Lanes

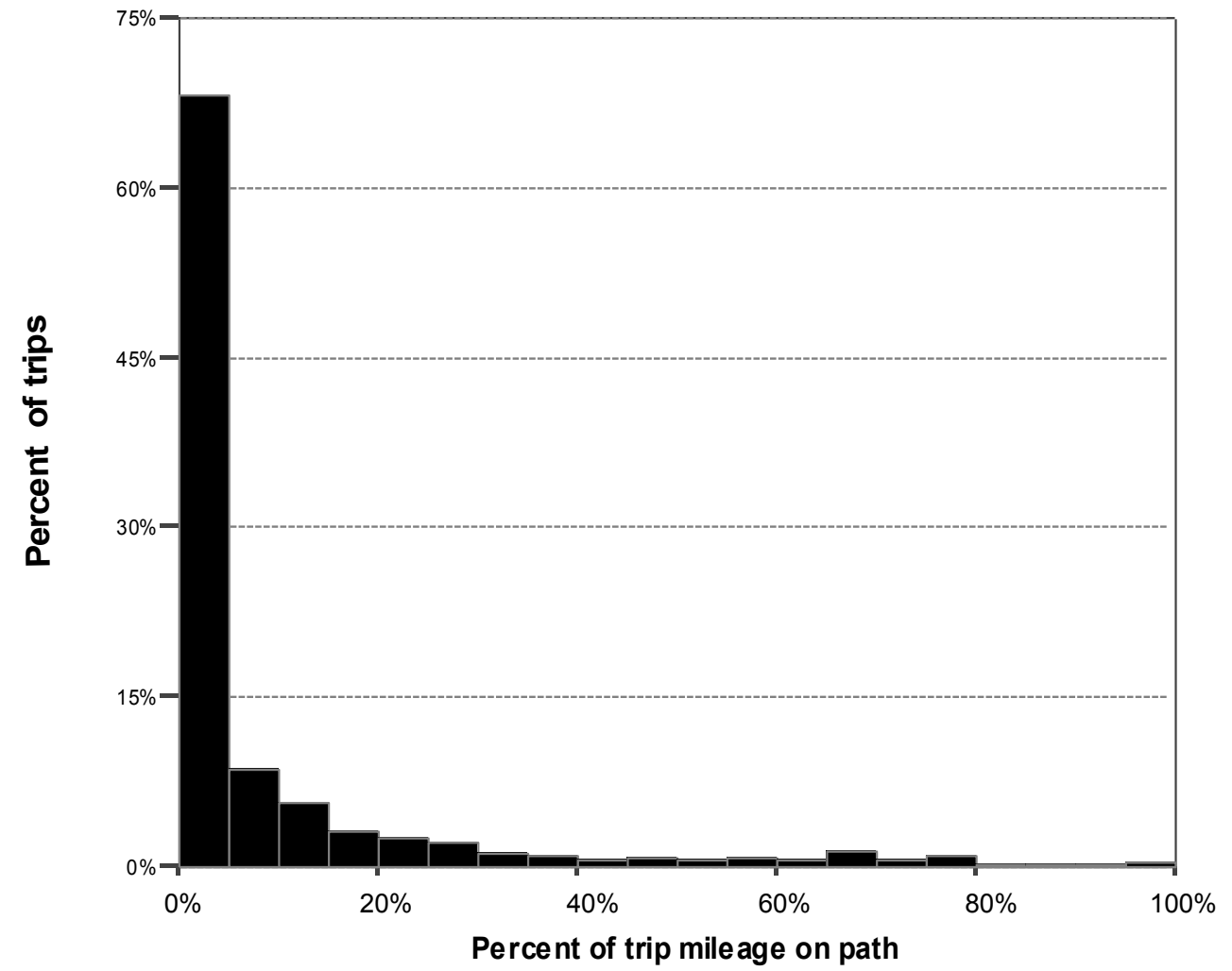

Figure 3.5 Distribution of Trips by Percent of Trip Mileage on Multi-use Paths 


\subsection{COMPARING ROUTE CHOICES}

\subsubsection{Observed Bicycle Route vs. Shortest Path}

Shortest paths were identified for 1,599 trips that met the following criteria: (1) made $100 \%$ on bicycle; (2) started and ended at least 200 feet apart; and (3) were not for exercise or an organized ride. The shortest-path methodology was explained in section 0 . Nearly all of the shortest paths were shorter in distance than the observed bicycle trips. The average difference was 0.95 miles, though the median was 0.27 miles. (There were several outliers that must be examined more closely.) This means that for half of the trips, the bicyclists rode 0.27 miles farther than the shortest path. At an average speed of 10.8 miles per hour, this would be about 1.5 extra minutes. The difference between the shortest path and the observed route increases with trip distance (Figure 3.6).

Looking only at the trips 10 miles or shorter, the median difference between the observed route and the shortest path was just under a quarter mile (0.24 miles). The cumulative distribution of the difference for these trips is shown in Figure 3.7. All but one percent of the trips were less than five miles long. This $1 \%$ is excluded from the figure for clarity. The bicycle trips averaged $17 \%$ longer in distance than the shortest-path routes (median $=11 \%)$. As with the absolute difference, the percentage difference increases with trip distance (Figure 3.8).

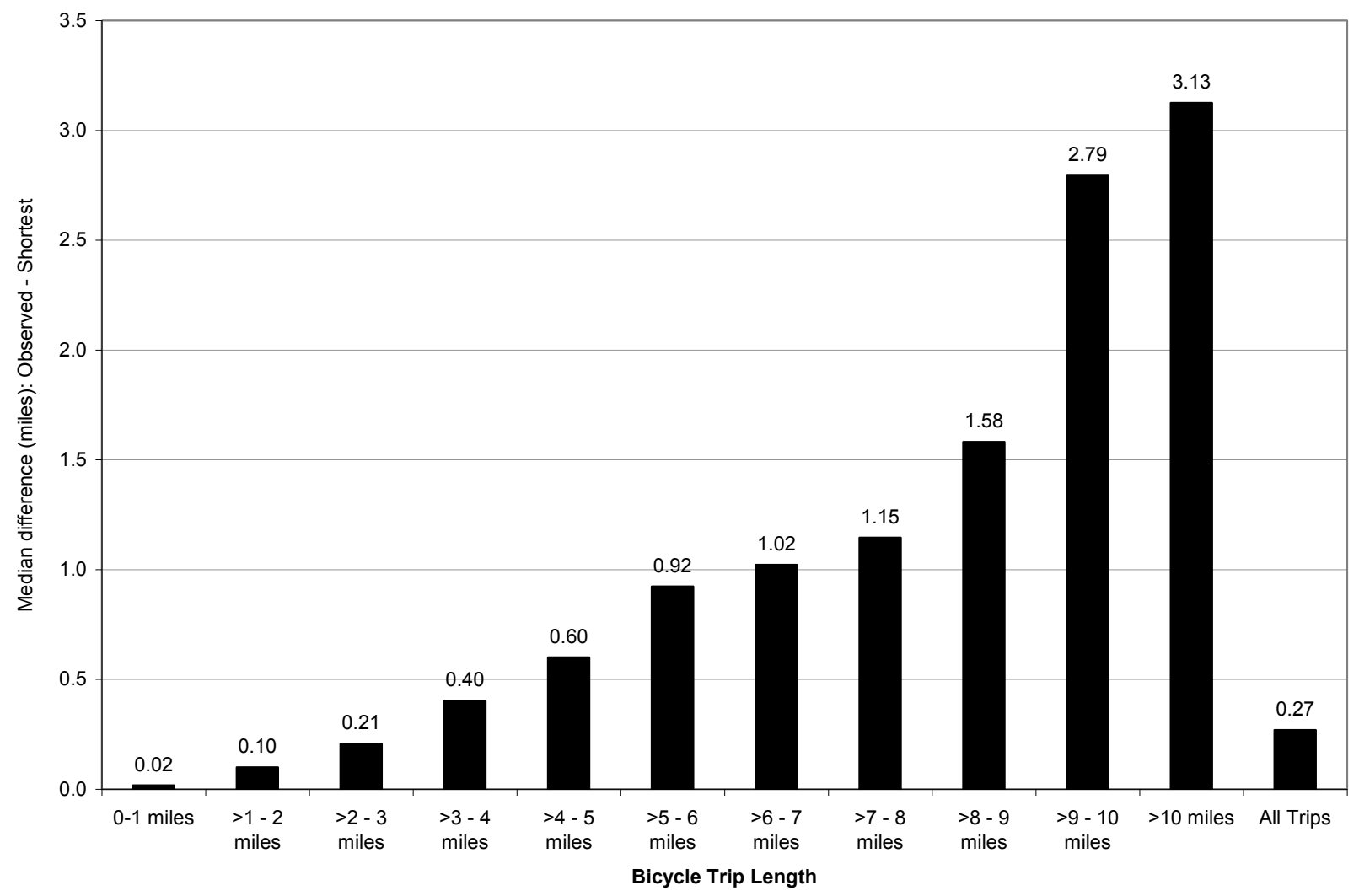

Figure 3.6 Median Difference (miles) between Observed and Shortest Route, by Trip Length 


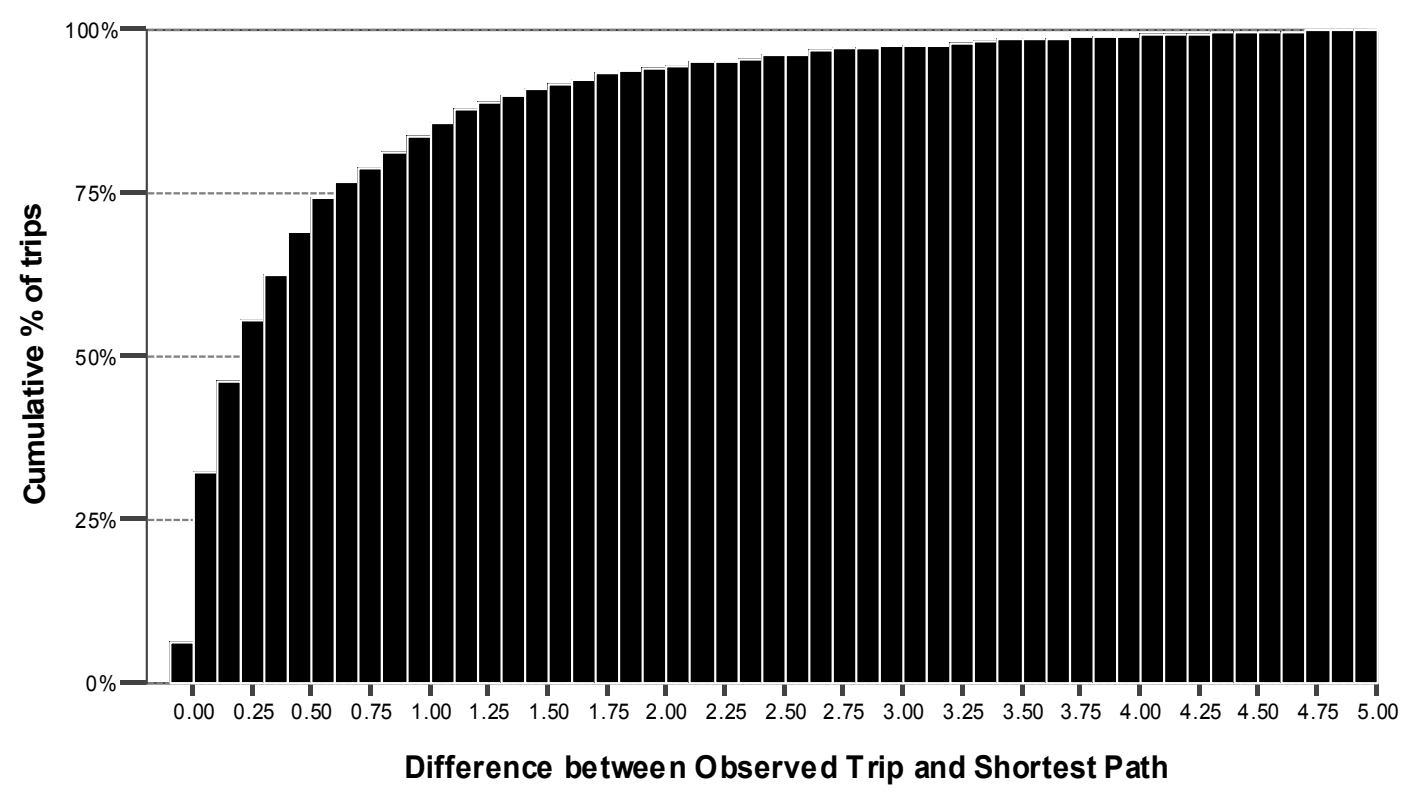

Figure 3.7 Difference (Miles) between Observed and Shortest Path for Trips 10 miles or Less, Cumulative Frequency

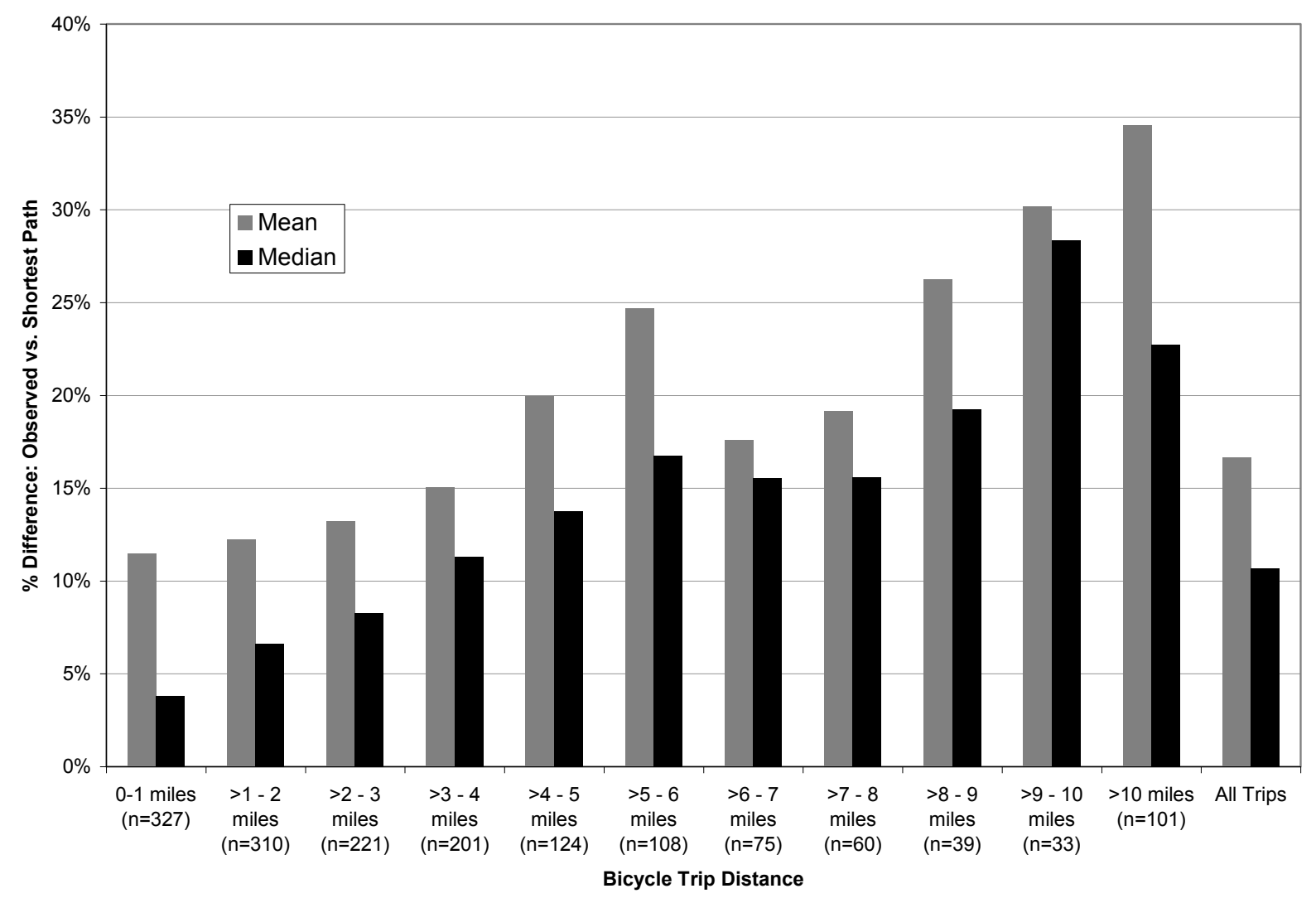

Figure 3.8 Percentage Difference between Observed and Shortest Route, by Trip Length 
Comparing the facilities used for the observed trips to the shortest paths reveals some preferences in facility type (Table 3.21). Adding all of the 1,599 trips together, the bicyclists traveled 6,131 miles. The shortest path routes for those trips totaled 4,629 miles. Bicyclists spent a higher share of their miles on facilities with bicycle infrastructure and on low-traffic streets than the shortest paths predicted. In particular, they rode $14 \%$ of their miles on paths, compared with $6 \%$ of the miles for the shortest paths, a difference of eight percentage points. Many bicyclists are avoiding arterials and highways that do not have bike lanes. Those facilities represented $19 \%$ of the bicyclists' miles, compared to $36 \%$ of the shortest-path miles. This also indicates that the major streets without bike lanes are often part of the shortest path between two points.

Table 3.21 Difference in Bicycle Travel by Facility Type, Observed vs. Shortest-Path Routes

\begin{tabular}{|c|c|c|c|c|c|}
\hline \multirow[b]{2}{*}{ Facility Type } & \multicolumn{2}{|c|}{ Observed Bicycle Trips } & \multicolumn{2}{|c|}{ Shortest-Path Routes } & \multirow{2}{*}{$\begin{array}{c}\text { \% Point } \\
\text { Difference in } \\
\text { Share of Miles } \\
\text { (Observed - } \\
\text { Shortest) }\end{array}$} \\
\hline & Miles & $\%$ of Miles & Miles & $\%$ of Miles & \\
\hline Arterials or highways, no bike lanes & 1,149 & $19 \%$ & 1,656 & $36 \%$ & $-17 \%$ \\
\hline $\begin{array}{l}\text { Low-traffic streets, no bike lanes } \\
\text { (including bicycle boulevards) }\end{array}$ & 2,569 & $42 \%$ & 1,663 & $36 \%$ & $6 \%$ \\
\hline Streets with bike lanes & 1,708 & $28 \%$ & 1,115 & $24 \%$ & $4 \%$ \\
\hline Bicycle boulevard & 623 & $10 \%$ & 206 & $4 \%$ & $6 \%$ \\
\hline Multi-use paths & 838 & $14 \%$ & 259 & $6 \%$ & $8 \%$ \\
\hline
\end{tabular}

Comparing the facilities used by men and women vs. the shortest-path routes reveals some differences. Men rode 4,003 miles, 38\% longer than the 2,904 miles predicted by the shortest paths. Women rode 2,097 miles, 24\% longer than the 1,686 miles for the shortest-path routes. Men's trips tend to be longer, and longer trips tend to be even longer than the shortest-path trips. This may explain part of the difference in the $38 \%$ vs. $24 \%$ difference between the observed and shortest-path totals. Looking at the percentage point differences between the observed and shortest paths, it appears that women are more likely to differ from the shortest path to use lowtraffic streets and bicycle boulevards. They appear slightly less likely to go out of their way to use streets with bike lanes. 
Table 3.22 Difference in Bicycle Travel by Facility Type, Observed vs. Shortest-Path Routes, Men and Women

\begin{tabular}{l|c|c|c|c|c|c}
\hline & \multicolumn{3}{|c|}{$\begin{array}{c}\text { Men } \\
\text { (864 Trips) }\end{array}$} & \multicolumn{3}{c}{$\begin{array}{c}\text { Women } \\
\text { (713 Trips) }\end{array}$} \\
\cline { 2 - 7 } \multicolumn{1}{c|}{ Facility Type } & $\begin{array}{c}\text { Observed } \\
\text { Bicycle } \\
\text { Trips }\end{array}$ & $\begin{array}{c}\text { Shortest- } \\
\text { Path } \\
\text { Routes }\end{array}$ & $\begin{array}{c}\text { \% Point } \\
\text { Diff. }\end{array}$ & $\begin{array}{c}\text { Observed } \\
\text { Bicycle } \\
\text { Trips }\end{array}$ & $\begin{array}{c}\text { Shortest- } \\
\text { Path } \\
\text { Routes }\end{array}$ & $\begin{array}{c}\% \text { Point } \\
\text { Diff. }\end{array}$ \\
\hline $\begin{array}{l}\text { Arterials or highways, no } \\
\text { bike lanes }\end{array}$ & $20 \%$ & $38 \%$ & $-18 \%$ & $15 \%$ & $32 \%$ & $-16 \%$ \\
\hline $\begin{array}{l}\text { Low-traffic streets, no bike } \\
\text { lanes } \\
\text { (including bicycle } \\
\text { boulevards) }\end{array}$ & $36 \%$ & $31 \%$ & $5 \%$ & $51 \%$ & $42 \%$ & $9 \%$ \\
\hline Streets with bike lanes & $30 \%$ & $25 \%$ & $4 \%$ & $24 \%$ & $22 \%$ & $2 \%$ \\
\hline Bicycle boulevard & $8 \%$ & $4 \%$ & $5 \%$ & $13 \%$ & $5 \%$ & $8 \%$ \\
\hline Multi-use paths & $15 \%$ & $6 \%$ & $8 \%$ & $12 \%$ & $5 \%$ & $7 \%$ \\
\hline
\end{tabular}

A similar comparison between frequent and infrequent bicyclists (10 or more days of bicycling per summer month) reveals some larger differences. In particular, infrequent bicyclists showed a strong preference to use multi-use paths, which represented $20 \%$ of their mileage, compared to $7 \%$ of the miles for their shortest-path routes. While $24 \%$ of their miles were on streets with bike lanes, the shortest paths predicted that $25 \%$ of their mileage would be on such roads. This indicates that infrequent bicyclists may not be going out of their way to use streets with bike lanes.

Table 3.23 Difference in Bicycle Travel by Facility Type, Observed vs. Shortest-Path Routes, Frequent and Infrequent Bicyclists

\begin{tabular}{|c|c|c|c|c|c|c|}
\hline \multirow[b]{2}{*}{ Facility Type } & \multicolumn{3}{|c|}{$\begin{array}{c}\text { Frequent Bicyclists } \\
\text { (>10 Days/Month in Summer) } \\
(1,337 \text { Trips) }\end{array}$} & \multicolumn{3}{|c|}{$\begin{array}{c}\text { Infrequent Bicyclists } \\
\text { (10 or Fewer Days/Month in Summer) } \\
\text { (204 Trips) } \\
\end{array}$} \\
\hline & $\begin{array}{c}\text { Observed } \\
\text { Bicycle } \\
\text { Trips }\end{array}$ & $\begin{array}{l}\text { Shortest- } \\
\text { Path } \\
\text { Routes }\end{array}$ & $\begin{array}{l}\text { \% Point } \\
\text { Diff. }\end{array}$ & $\begin{array}{c}\text { Observed } \\
\text { Bicycle } \\
\text { Trips }\end{array}$ & $\begin{array}{l}\text { Shortest- } \\
\text { Path } \\
\text { Routes }\end{array}$ & $\begin{array}{l}\text { \% Point } \\
\text { Diff. }\end{array}$ \\
\hline $\begin{array}{l}\text { Arterials or highways, no bike } \\
\text { lanes }\end{array}$ & $19 \%$ & $36 \%$ & $-17 \%$ & $16 \%$ & $34 \%$ & $-17 \%$ \\
\hline $\begin{array}{l}\text { Low-traffic streets, no bike } \\
\text { lanes } \\
\text { (including bicycle boulevards) }\end{array}$ & $41 \%$ & $35 \%$ & $6 \%$ & $40 \%$ & $33 \%$ & $7 \%$ \\
\hline Streets with bike lanes & $29 \%$ & $24 \%$ & $5 \%$ & $24 \%$ & $25 \%$ & $-1 \%$ \\
\hline Bicycle boulevard & $11 \%$ & $4 \%$ & $6 \%$ & $6 \%$ & $4 \%$ & $1 \%$ \\
\hline Multi-use paths & $13 \%$ & $5 \%$ & $7 \%$ & $20 \%$ & $7 \%$ & $13 \%$ \\
\hline
\end{tabular}




\subsubsection{Bicycle vs. Car Travel Time}

The travel time in a motorized vehicle was estimated for 1,422 of the trips, using the method described in section 2.6. ${ }^{5}$ The analysis does not include the time to park (either the bicycle or the motor vehicle) or walk between the parking place and the final destination. On average, the bicycle trips were 13.4 minutes longer than the estimated auto travel time. The median difference was 9.5 minutes. For $26 \%$ of the trips, the bicycle trip was less than five minutes longer (Table 3.24). For shorter trips, half of the bicycle trips were less than five minutes longer. The mean differences in travel times by trip distance are shown in Figure 3.9.

Table 3.24 Observed Bicycle vs. Predicted Motor Vehicle Travel Times

\begin{tabular}{l|c|c}
\hline $\begin{array}{l}\text { Difference In Travel Time } \\
\text { (Actual Bicycle Travel Time Minus } \\
\text { Estimated Auto Travel Time) }\end{array}$ & $\begin{array}{c}\text { \%o of All } \\
\text { Bicycle Trips }\end{array}$ & $\begin{array}{c}\text { \% of Bicycle } \\
\text { Trips 3 Miles } \\
\text { or Shorter }\end{array}$ \\
\hline Bicycle travel time is faster & $<1 \%$ & $1 \%$ \\
\hline Bicycle travel time is... & & \\
\hline $0-4.99$ minutes longer & $26 \%$ & $49 \%$ \\
\hline$>5-9.99$ minutes longer & $26 \%$ & $38 \%$ \\
\hline$>10-14.99$ minutes longer & $18 \%$ & $9 \%$ \\
\hline$>15-19.99$ minutes longer & $9 \%$ & $2 \%$ \\
\hline More than 20 minutes longer & $21 \%$ & $<1 \%$ \\
\hline $\mathrm{n}$ & 1,422 & 747 \\
\hline
\end{tabular}

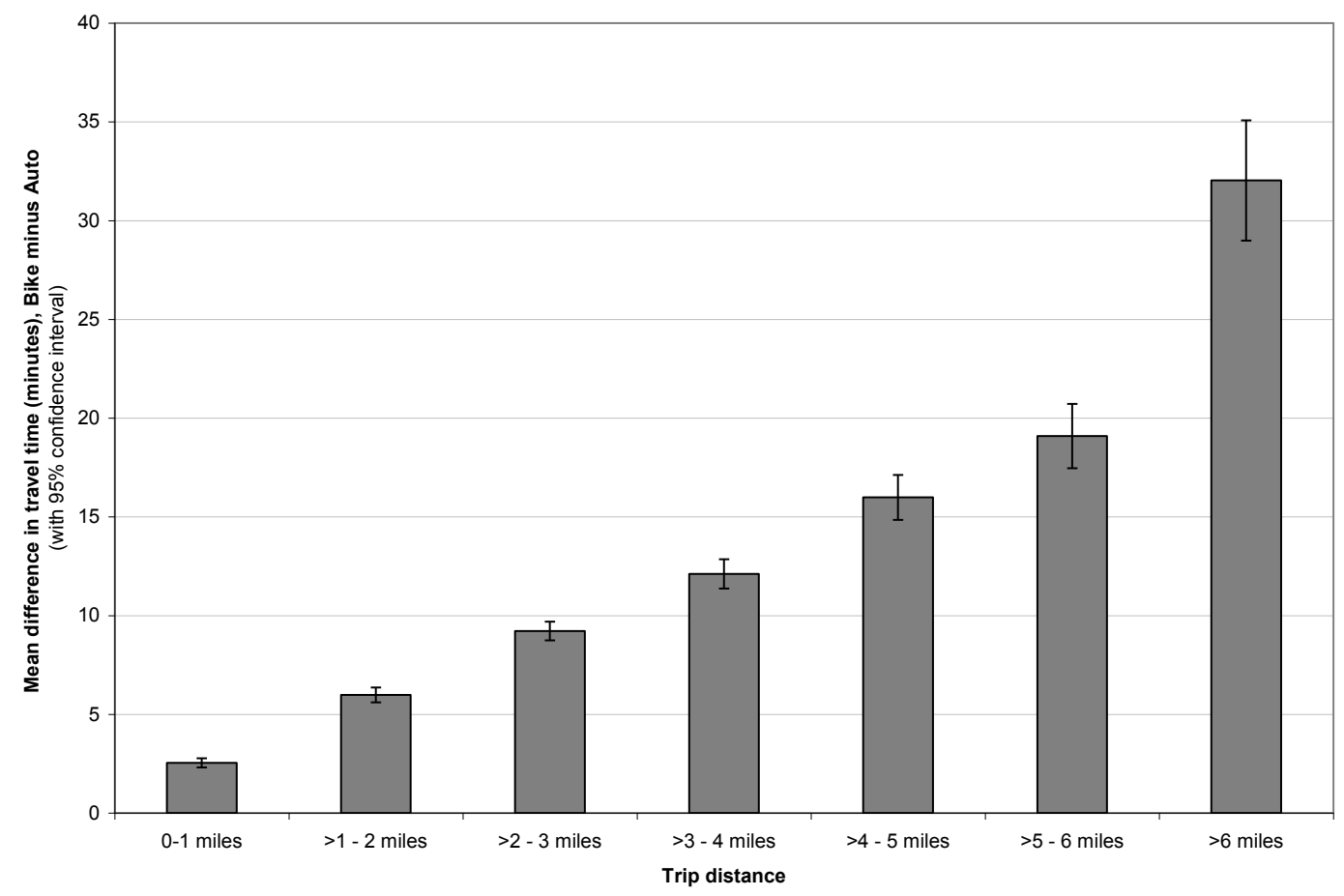

Figure 3.9 Difference between Observed Bicycle and Predicted Motor Vehicle Travel Times (minutes), by Trip Distance

\footnotetext{
${ }^{5}$ Auto travel times were not estimated for loop trips and trips where a portion of the trip was not on a bike.
} 


\subsection{CONCLUSIONS}

\subsection{KEY FINDINGS}

\subsubsection{How Often, Why, When, and Where Do Cyclists Ride?}

The participants in this study were primarily regular bicyclists. While participating in the study, they made an average of 1.6 bicycle trips per day. Most participants (77\%) made an average of two or fewer bicycle trips per day while they had the GPS device. Participants rode an average of 6.2 miles per day. Just over half (51\%) of the participants bicycled less than five miles per day and $85 \%$ bicycled less than 10 miles per day. The median bicycle trip distance was 2.8 miles. Exercise trips were significantly longer (median distance of 8.5 miles). Trips to work were a median distance of 3.8 miles, while trips for other purposes were significantly shorter, usually ranging from one to two miles. Bicyclists rode an average of 10.8 miles per hour, including time stopped at intersections, etc.

The vast majority of the bicycle travel recorded by the participants was for utilitarian purposes. Only $5 \%$ of the trips were purely for exercise. Aside from riding back home, riding to work was the most frequent trip purpose (25\%). About $18 \%$ was for shopping, dining out, or other personal business, and $12 \%$ was for social/recreation purposes (such as going to the movies, the gym, or visiting friends).

About half of the trips occurred during morning and evening peak travel times (6-9 a.m. and 4-7 p.m.), with about one-third occurring between those time periods. Therefore, less than $20 \%$ of the trips occurred in the late evening and very early morning. This indicates that most bicycling occurs during daylight hours.

When the bicyclists were riding for utilitarian purposes, they rode mainly on facilities with bicycle infrastructure. Over half (52\%) of the miles on bicycle-only utilitarian trips were made on facilities with bicycle infrastructure, including lanes, separate paths, or bicycle boulevards. Over one-quarter of the mileage (28\%) occurred on streets (arterials or minor streets) with bike lanes. An equal share (28\%) occurred on minor streets without bike lanes. These are typically low traffic volume, residential streets. Therefore, only $19 \%$ of the travel was on streets that would be expected to have high volumes of motor vehicle traffic and no separate facility for a bicycle. Bicycling for exercise followed a different pattern. Nearly two-thirds (64\%) of this travel was on roads without bike lanes. This reflects, in part, a significant amount of exercise travel in more rural areas. Overall, smaller shares of the exercise riding occurred on more urban facilities - streets with bike lanes and bicycle boulevards. The exception is the use of regional multi-use paths; $15 \%$ of the exercise travel occurred on these facilities.

\subsubsection{How Do Cyclists' Routes Differ from the Shortest Network Distance?}

The average difference in distance between the actual bicycle trip and the shortest path between the same origin and destination was 0.95 miles, though the median was 0.27 miles. The 
difference between the shortest path and the observed route increases with trip distance. Looking only at the trips 10 miles or shorter in distance, the median difference between the observed route and the shortest path was just under a quarter mile $(0.24$ miles $)$. This represents about an extra 1.5 minutes of travel, given the average speed on the trips.

Comparing the facilities used for the observed trips to the shortest paths reveals some preferences in facility type. Bicyclists spent a higher share of their miles on facilities with bicycle infrastructure and on low-traffic streets than the shortest paths predicted. In particular, they rode $14 \%$ of their miles on paths, compared with $6 \%$ of the miles for the shortest paths, a difference of eight percentage points. Many bicyclists are avoiding arterials and highways that do not have bike lanes. Those facilities represented 19\% of the bicyclists' miles, compared with $36 \%$ of the shortest-path miles. This also indicates that the major streets without bike lanes are often part of the shortest path between two points.

\subsubsection{How Do Cyclists Choose Their Routes?}

When asked about their route choices and preferences for utilitarian trips, participants placed highest importance on minimizing distance and avoiding streets with lots of vehicle traffic. Riding on a street with a bicycle lane was usually ranked third in importance, followed by reducing waiting time at stop lights and signs. These top four preferences reflect two sometimes conflicting sets of objectives. Most utilitarian bicyclists want to minimize their travel time. That is a fundamental assumption in travel demand modeling and planning for all travelers, no matter the mode (car, transit, etc). However, depending upon the network available, the quickest route for bicyclists may not satisfy their second major set of objectives, which is related to avoiding motor vehicle traffic.

\subsubsection{How Does This Vary Based Upon Rider Characteristics?}

\subsubsection{Differences between Men and Women}

In most large U.S. urban areas, including Portland, women are less likely to be regular, utilitarian bicyclists. Therefore, if cities hope to increase overall bicycling rates, the share of women riding must increase significantly. This study oversampled for women so their travel could be compared to men's. Men and women participating in the study made about the same number of trips per day, though women bicycled significantly fewer miles per day. Women also bicycled at slower speeds, averaging 9.8 miles per hour, compared to 11.6 for men.

When asked about route choices, women ranked the factors in the same order as men, on average. However, they rated all but one of the factors - riding in a bike lane - higher than men on the one-to-five scale. For three factors, the difference was significant: minimizing distance, avoiding streets with lots of traffic, and avoiding hills.

This difference in stated preferences is reflected in the women's actual bicycle routes. Women rode a smaller share of their miles on major roads (arterials and highways) with or without bike lanes compared to men. They bicycled more often on low-traffic streets and on bicycle boulevards. Some of this difference is due to where the participants lived 
and where they were bicycling to. Therefore, it is useful to compare the observed routes to the shortest-path routes. Making this comparison, women appear more likely to go out of their way to bicycle on low-traffic streets and bicycle boulevards, and slightly less likely to go out of their way to use streets with bike lanes.

\subsubsection{Difference between Infrequent and Frequent Bicyclists}

Because a major objective of this research is to explore what changes could be made to urban areas to increase rates of bicycling, another useful comparison is between people who bicycle a lot vs. those who bicycle less often. The sample did not have a large number of very infrequent bicyclists (less than once a week). The sample was divided into groups based upon bicycling frequency in the summer and non-summer months. While the relative rankings of factors influencing route choice were similar between the groups, there were differences in the average ratings, using the 1-5 scale, with five being very important.

Participants who bicycled 10 or fewer days per month in the summer placed less importance on riding in bicycle lanes, on signed bike routes, or on reducing wait times at stops signs and lights. Participants who bicycled four or fewer days per month in the nonsummer months placed higher importance on avoiding streets with lots of traffic, riding on paths/trails, and avoiding hills. These findings generally indicate that less experienced bicyclists place higher importance on factors that make the trip easier - routes with less traffic and requiring less physical effort. Looking at their bicycle travel, the participants who bicycled less frequently in the summer months were more likely to go out of their way (diverted more from the shortest path) to use multi-use paths. They were less likely to divert from the shortest path to use a street with a bike lane.

\subsubsection{What Is the Difference in Travel Time between Bicycling and Driving?}

For most of the trips, a travel time in a motorized vehicle was estimated for the fastest trip between the same origin and destination. The estimated time does not include the time to park (either the bicycle or the motor vehicle) or walk between the parking place and the final destination. On average, the bicycle trips were 13.4 minutes longer than the estimated auto travel time. The median difference was 9.5 minutes. For $26 \%$ of the trips, the bicycle trip was less than five minutes longer (Table 3.24). For shorter trips, half of the bicycle trips were less than five minutes longer.

\subsubsection{Policy Implications}

Regular bicyclists in the Portland region are going out of their way to use the bicycle infrastructure provided, including streets with bike lanes, separate paths, and bicycle boulevards. Over half of all of their bicycle travel occurred on these facilities, while only just over one-third would have if they had taken the shortest-distance route available. This indicates that bicyclists value the facilities because they are spending extra time or effort to use them. This is consistent with their stated preferences for traveling on routes without a lot of vehicle traffic. 
Women and people who bicycle less frequently appear to be more concerned about bicycling on facilities with a lot of motor vehicle traffic, including bicycle lanes on major streets. Many of these bicyclists stated and revealed a preference for low-traffic streets, bicycle boulevards, and separate paths. This indicates that these types of facilities may be more effective at getting more women and infrequent or non-cyclists to ride.

All bicyclists placed very high importance on minimizing travel distances. A well-connected network is necessary to minimize travel distances. Neighborhoods with a grid street pattern and small blocks will have higher connectivity than areas with lots of cul-de-sacs and/or large blocks. Those are also locations were bicycle boulevards can more easily be implemented - where a low-traffic street parallels and high-traffic street. Most neighborhoods built prior to World War II were built with this type of street system. In many U.S. suburbs built since, street connectivity can be poor. However, the Portland region has connectivity standards that help ensure higher levels in new developments.

While the data indicate that bicycle boulevards and paths may be more effective than bike lanes on arterials at encouraging more bicycling among groups of people who currently do not bicycle much, the importance of bike lanes should not be ignored. Over one-quarter (28\%) of all of bicycle travel occurred on streets with bike lanes, compared to $24 \%$ that was predicted to occur using the shortest paths. Moreover, the analysis indicated that $36 \%$ of the travel would have occurred on arterials and highways without bike lanes if the bicyclists chose the shortest routes. Only $19 \%$ of the actual bicycle travel occurred on these facilities. This indicates that major streets without bike lanes are often the shortest and perhaps fastest way to travel between two points, yet most bicyclists are avoiding them. Providing bike lanes on such streets may reduce travel distances and times for bicyclists, which could encourage more bicycling. More experienced bicyclists were more likely than less experienced bicyclists to go out of their way to use streets with bike lanes. Therefore, lanes on major streets are important to these bicyclists.

For the bicycle to increase its share of utilitarian travel it must have some advantages over other modes, including the automobile. For most travelers, including bicyclists, time is a key factor in mode choice. The data from this study found that the bicycle may be time-competitive with the automobile for many short trips. For half of the shorter trips (three miles or less), the bicycle travel time is less than five minutes longer than the predicted auto travel time. Shorter trips are most likely to occur in areas with a greater mix of land uses and higher network connectivity, making potential origins and destinations closer. Therefore, policies that promote these features are likely to support more bicycling for transportation. Further analysis of this data will reveal more about where and when the bicycle is most competitive with auto travel. In addition, some non-cyclists or less-frequent cyclists may not realize that bicycle travel in some cases is timecompetitive with traveling by car. Education programs and signage may overcome this obstacle.

\subsection{LIMITATIONS}

While this study collected more detailed information on bicycling behavior than any other studies found in the literature, there are still many limitations. One obvious limitation is that the study was only conducted in one region. Caution must always be used when conclusions based upon data from one area are used to make recommendations for another area. 
However, there are also reasons why the Portland region was particularly useful for this research. While Portland is widely regarded as an excellent large U.S. city for bicycling, the quality of the bicycling environment and level of street connectivity varies significantly within the city and across the region. In addition, the City of Portland has perhaps the largest network of bicycle boulevards of any large city in the U.S., making it one of the few places this type of infrastructure could be studied. It would not be useful to conduct this type of study in a region with very few bike lanes, paths or other options. The value of the data comes from being able to see where and why people make choices between clear options (e.g., traveling an extra few minutes to use a bike lane).

The bicyclists participating in this study do not represent all bicyclists. The sample included primarily regular cyclists who bike mainly for utilitarian purposes. In contrast, the majority of bicycle trips made by adults in the U.S. are for exercise purposes. Based upon the phone survey findings from an earlier phase of this research, over $80 \%$ of bicyclists identify themselves as "occasional" riders and the remaining $20 \%$ are "regular" bicyclists. The sample in this study was about the opposite, with $83 \%$ self-identified as regular bicyclists and $17 \%$ as occasional.

The second phase of the recruitment effort specifically asked for people who bicycled less than four days a week. While this effort was moderately successful, the sample of occasional bicyclists is still relatively small. This makes it more difficult, though not impossible, to draw conclusions about the behavior of infrequent cyclists. The predominance of utilitarian bicyclists is perhaps less of a problem. A main objective of this research is to understand what local and regional governments can do to change infrastructure and the physical environment to encourage more bicycling for transportation purposes. The data indicated that route preferences are very different for exercise trips, and that these trips often occur outside of urban areas. Therefore, different solutions are likely necessary to encourage utilitarian bicycle travel relative to bicycling for exercise purposes only.

The GPS units presented a few limitations. Some of these limitations were discussed in the methodology section, including potential errors when linking the GPS point data to the network. In addition, the unit required a special attachment or rack and had a limited battery life. Because of this, it was expected that some participants would not take the unit on some trips, either on purpose or by accident, or that the unit would not record some trips due to a dead battery.

The follow-up survey asked about missed trips. Over half (56\%) of the participants indicated that all of their bicycle trips were recorded. For those that indicated that some trips were missing, they indicated that a total of 177 trips were not recorded. This represents $9 \%$ of the trips recorded $(1,955)$. Therefore, bicycle trips may be underreported by about $8 \%$. The cited reasons for the missed trips included having the device on the trip but it did not record the trip (37\%), dead batteries (27\%), forgetting to take the unit (19\%), and not taking the device on purpose (1\%).

Another potential issue is that participation in the study and carrying the GPS device could influence cyclists' behavior. Attempts were made to reduce this by making the screen blank while riding and instructing the participant to ride as they normally would. The follow-up survey asked participants how the number of trips recorded during the study period compared to the number as they normally would make. Over two-thirds $(68 \%)$ said that the number was about the same and $9 \%$ said that they made more trips. Of those $9 \%, 79 \%$ cited factors such as weather and 
changes in their lives (e.g., retiring or moving) that explained the increase. Only one person admitted that they rode more than normal because of being in the study. Twelve percent of the participants said that having the GPS device changed their bicycle behavior. When asked to explain how, the participants responded as follows:

\section{Usability Issues}

- Just that it was something extra to keep track of.

- It was necessary to spend time getting it going and taking care of the equipment. Once, the unit fell off its perch when I hit a bump but it appears not to have noticed it. I retrieved it quickly and remounted so it was none the wiser, I guess. Other than that incident, you have a very accurate picture of my year round weekly riding behavior.

- I had to wait for it to for the unit to start logging rather than jumping on to the bike.

- I had to spend a little extra time getting the PDA/GPS device set and in place. It did not change where or how much I biked, just how quickly I got set up to ride.

- It fell off once

- I kept stopping and checking it and finding out it had turned itself off, so I had to restart it, then stop and check it repeatedly and still it missed lots of route data

\section{Changes in routes and amount of riding}

- There was one or two times that I varied my route a bit knowing that it was being recorded. But most of the time it did not change my behavior at all.

- slowed me down a little bit. maybe made me want to ride a little more. but generally, no.

- On a few (3 or fewer) times I walked instead of using the bike w/GPS partially due to the unreliability of the unit I was using was more hassle to mount the unit, initialize/turn on and get the purpose logged in with WX etc than to just walk there especially since my unit was frequently malfunctioning.

- I think I'm probably typically a bit more lazy about riding. My goal is once or twice a week, but if it's rainy, that usually goes out the window.

- I probably wouldn't have ridden at all the week in question if I hadn't had the devise. Also, I'm more motivated now to ride, although the rain isn't helping!

- Helped keep up my motivation to commute every day.

- I didn't stop much, wanted to be sure the GPS was recording.

- As stated above, I simply rode more often so that I could record more of my customary rides. The routes were not affected that I am aware of.

\section{Unclear/Other}

- It showed me how to develop an unofficial 'bike route' that could be shared with other bicyclists in the area via the internet or GPS download.

- It motivated me to record my routes.

- It made it more fun to take my bike out! 
- I was more conscious of my route choice than I might have been otherwise, but not enough to change my routes.

\subsection{NEXT STEPS}

This study generated a large amount of detailed data on bicycling behavior among regular bicyclists in the Portland region. This report only presented some of the key findings addressing the major research questions. Further analysis, including more multivariate discrete choice modeling, is necessary to more fully answer the questions. Such analysis will help reveal the relative value different types of bicyclists place on the different facility types. 


\section{REFERENCES}

Aultman-Hall, Lisa, Fred L. Hall, and Brian B. Baetz. 1998. Analysis of Bicycle Commuter Routes Using Geographic Information Systems: Implications for Bicycle Planning. Transportation Research Record 1578:102-110.

Bassett, David R. Jr., John Pucher, Ralph Buehler, Dixie L. Thompson, and Scott E. Crouter. 2008. Walking, Cycling, and Obesity Rates in Europe, North America, and Australia. Journal of Physical Activity and Health 5:795-814.

Buehler, Ted, and Susan Handy. 2008. Fifty years of bicycle policy in Davis, CA. Paper read at 87th Annual Meeting of the Transportation Research Board, at Washington, DC.

Bureau of Transportation Statistics. 2000. Bicycle and Pedestrian Data: Sources, Needs, \& Gaps. Washington, DC: U.S. Department of Transportation.

- 2004. How Bike Paths and Lanes Make a Difference. In BTS Issue Brief. Washington, DC: Bureau of Transportation Statistics.

Centers for Disease Control and Prevention. 2003. Prevalence of Physical Activity, Including Lifestayle Activities Among Adults -- United States, 2000-2001. Review of Reviewed Item. MMWR Weekly (32), http://www.cdc.gov/MMWR/preview/mmwrhtml/mm5232a2.htm.

Dill, Jennifer. 2007. Getting from Here to There in the Region. In Metropolitan Briefing Book, edited by S. Martin and C. Wollner. Portland, OR: Institute of Portland Metropolitan Studies, Portland State University.

Dill, Jennifer, and Theresa Carr. 2003. Bicycle Commuting and Facilities in Major U.S. Cities: If You Build Them, Commuters Will Use Them. Transportation Research Record Journal of the Transportation Research Board 1828:116-123.

Dill, Jennifer, and Kim Voros. 2007. Factors Affecting Bicycling Demand: Initial Survey Findings from the Portland, Oregon, Region. Transportation Research Record: Journal of the Transportation Research Board 2031:pp 9-17.

Federal Highway Administration. 1992. National Bicycling and Walking Study, Case Study No. 1: Reasons Why Bicycling and Walking Are Not Being Used More Extensively As Travel Modes. Washington, DC.: U.S. Department of Transportation.

Garrard, J., G. Rose, and S. K. Lo. 2008. Promoting transportation cycling for women: The role of bicycle infrastructure. Preventive Medicine 46 (1):55-59.

Health Canada. 1998. 1998 National Survey on Active Transportation Summary Report: Go for Green 
Howard, Charlene, and Elizabeth K. Burns. 2001. Cycling to Work in Phoenix: Route Choice, Travel Behavior, and Commuter Characteristics. Transportation Research Record 1773:3946.

Hunt, J. D., and J. E. Abraham. 2007. Influences on bicycle use. Transportation 34 (4):453-470.

Krizek, K. J. 2006. Two approaches to valuing dome of bicycle facilities' presumed benefits. Journal of the American Planning Association 72 (3):309-320.

Krizek, Kevin J., Ahmed El-Geneidy, and Kristin Thompson. 2007. A detailed analysis of how an urban trail system affects cyclists' travel. Transportation 34 (5):611-624.

LeClerc, Mauricio. 2002. Bicycle Planning in the City of Portland: Evaluation of the City's Bicycle Master Plan and Statistical Analysis of the Relationship between the City's Bicycle Network and Bicycle Commute. Field Area Paper, School of Urban Studies and Planning, Portland State University, Portland, OR.

Moritz, William E. 1998. Survey of North American Bicycle Commuters: Design and Aggregate Results. Transportation Research Record 1578:91-101.

Murakami, E., and D. P. Wagner. 1999. Can using global positioning system (GPS) improve trip reporting? Transportation Research Part C: Emerging Technologies 7 (2-3):149-165.

National Highway Traffic Safety Administration, and Bureau of Transportation Statistics. 2003. National Survey of Pedestrian and Bicyclist Attitudes and Behaviors: Highlights Report. Washington, DC: U.S. Department of Transportation.

Nelson, Arthur C., and David Allen. 1997. If You Build Them, Commuters Will Use Them. Transportation Research Record 1578:79-83.

Plaut, Pnina O. 2005. Non-motorized commuting in the US. Transportation Research Part D 10:347-356.

Pucher, J., and R. Buehler. 2006. Why Canadians cycle more than Americans: A comparative analysis of bicycling trends and policies. Transport Policy 13 (3):265-279.

Pucher, John, and Lewis Dijkstra. 2000. Making walking and cycling safer: lessons from Europe. Transportation Quarterly 54 (3):25-50.

. 2003. Promoting Safe Walking and Cycling to Improve Public Health: Lessons From The Netherlands and Germany. American Journal of Public Health 93 (9):1509-1516.

Pucher, John, Charles Komanoff, and Paul Schimek. 1999. Bicycling renaissance in North America? Recent trends and alternative policies to promote bicycling. Transportation Research Part A 33:625-654.

Shafizadeh, Kevan, and Debbie Niemeier. 1997. Bicycle Journey-to-Work: Travel Behavior Characteristics and Spatial Analysis. Transportation Research Record 1578:84-90. 
Stinson, Monique; , and Chandra Bhat. 2003. Commuter Bicyclist Route Choice: Analysis using a Stated Preference Survey. Transportation Research Record 1828:107-115.

Tilahun, N. Y., D. M. Levinson, and K. J. Krizek. 2007. Trails, lanes, or traffic: Valuing bicycle facilities with an adaptive stated preference survey. Transportation Research Part a-Policy and Practice 41 (4):287-301.

Vernez-Moudon, A. V., C. Lee, A. D. Cheadle, C. W. Collier, D. Johnson, T. L. Schmid, and R. D. Weather. 2005. Cycling and the built environment, a US perspective. Transportation Research Part D-Transport and Environment 10 (3):245-261.

Xing, Yan, Susan L. Handy, and Theodore J. Buehler. 2008. Factors Associated with Bicycle Ownership and Use: A Study of 6 Small U.S. Cities. Paper read at 87th Annual Meeting of the Transportation Research Board, at Washington, DC. 
P.O. Box 751

Portland, OR 97207

www.otrec.us

OTREC is dedicated to stimulating and conducting collaborative multi-disciplinary research on multi-modal surface transportation issues, educating a diverse array of current practitioners and future leaders in the transportation field, and encouraging implementation of relevant research results. 